Utah State University

DigitalCommons@USU

\title{
8-2018
}

\section{Plume Contamination Measurements of an Additively-Printed GOX/ABS Hybrid Thruster}

David A. Brewer

Utah State University

Follow this and additional works at: https://digitalcommons.usu.edu/etd

Part of the Aerospace Engineering Commons

\section{Recommended Citation}

Brewer, David A., "Plume Contamination Measurements of an Additively-Printed GOX/ABS Hybrid Thruster" (2018). All Graduate Theses and Dissertations. 7072.

https://digitalcommons.usu.edu/etd/7072

This Thesis is brought to you for free and open access by the Graduate Studies at DigitalCommons@USU. It has been accepted for inclusion in All Graduate Theses and Dissertations by an authorized administrator of DigitalCommons@USU. For more information, please contact digitalcommons@usu.edu.

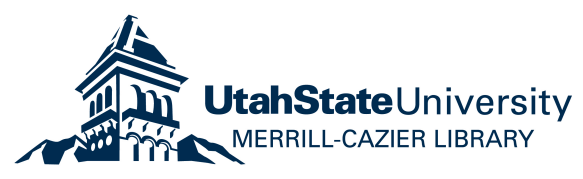




\section{PLUME CONTAMINATION MEASUREMENTS OF AN ADDITIVELY-PRINTED GOX/ABS HYBRID THRUSTER}

by

David A. Brewer

A thesis submitted in partial fulfillment

of the requirements for the degree

of

\section{MASTER OF SCIENCE}

in

Aerospace Engineering

Approved:

Stephen Whitmore, Ph.D

Major Professor

Geordie Richards, Ph.D

Committee Member

David Geller, Ph.D.

Mark R. McLellan, Ph.D.

Vice President for Research and

Dean of the School of Graduate Studies

UTAH STATE UNIVERSITY

Logan, Utah

2018 
Copyright (C) David A. Brewer 2018

All Rights Reserved 


\begin{abstract}
PLUME CONTAMINATION MEASUREMENTS OF AN ADDITIVELY-PRINTED

GOX/ABS HYBRID THRUSTER
\end{abstract}

by

David A. Brewer, Master of Science

Utah State University, 2018

\title{
Major Professor: Dr. Stephen A. Whitmore \\ Department: Mechanical and Aerospace Engineering
}

Historically, due to the lack of a reliable, on-demand, and multiple-use ignition methodology, hybrid rockets have never been previously considered for in-space propulsion. Recently, the Propulsion Research Laboratory at Utah State University has developed unique arc-ignition system that overcomes this problem and allows hybrids to be started, stopped, and restarted with a high degree of reliability, and requiring a low power input. The technology is derived from the unique electrical breakdown properties of 3-D printed plastics like ABS. Because ABS is an entirely new material for propulsion applications, and no database exists to describe the potential deleterious effects of the exhaust plume on spacecraft surfaces. Adsorption of propellant effluents on spacecraft surfaces can create multiple operational concerns; for example, deposition of molecules on solar arrays and thermal control surfaces can lead to decreased power production and increased spacecraft temperatures. This paper presents the results from a set of preliminary 
plume contamination measurements collected under both ambient and vacuum chamber conditions. The instrumentation suite used for these measurements is derived from sensors used to make hall-effect thruster plume contamination measurements on the USAF ESEX spacecraft. Generally, it is observed that when the motor operates at or near stoichiometric combustion, plume contamination effects are small. At oxidizer-to-fuel ratios significantly below stoichiometric, plume contamination effects become considerably larger. 
PUBLIC ABSTRACT

\title{
PLUME CONTAMINATION MEASUREMENTS OF AN ADDITIVELY-PRINTED GOX/ABS HYBRID THRUSTER
}

\author{
David A. Brewer
}

This thesis examines the impact of the physical contamination on optical surfaces of spacecraft by an ABS/GOX thruster. Plume contamination presents a significant operational hazard for spacecraft solar arrays and thermal control surfaces can lead to decreased power production and increased spacecraft temperatures. Historically, due to the lack of a reliable, ondemand, and multiple-use ignition methodology, hybrid rockets have never been previously considered for in-space propulsion. Recent advancements in hybrid rocket technologies, have made hybrid systems feasible for in space propulsion. However, prior to this study no research had ever been performed with regard to plume contamination effects due to hybrid rockets. This paper presents the results from a set of preliminary plume contamination measurements on a prototype small spacecraft hybrid rocket system, collected under both ambient and vacuum chamber conditions. 


\section{ACKNOWLEDGMENTS}

The authors would like to thank the NASA Marshall Space Flight Center for their continued funding of this project through a Multiple-Use Technologies Co-Operative Research Agreement, and the NASA Space Technology Research Fellowships. We would also like to thanks MSFC ER23 for providing access to the required NASA facilities including the vacuum chamber and instrumentation used to collect the presented data. We are especially grateful for ER-23 employees Kevin Pedersen and Carlos Diaz for their technical support and expert advice. Their subject matter expertise was a key asset allowing us to pull off this experiment. The Scanning Electron Microscope images were taken with the Scanning Electron Microscope and Energy Dispersive Spectroscopy in the USU Microscopy Core Facility. For the record, Carlos gave up his Christmas Break holiday period to help us complete the final set of tests that resulted in the plumecontamination data presented in this report. Thanks. 


\section{CONTENTS}

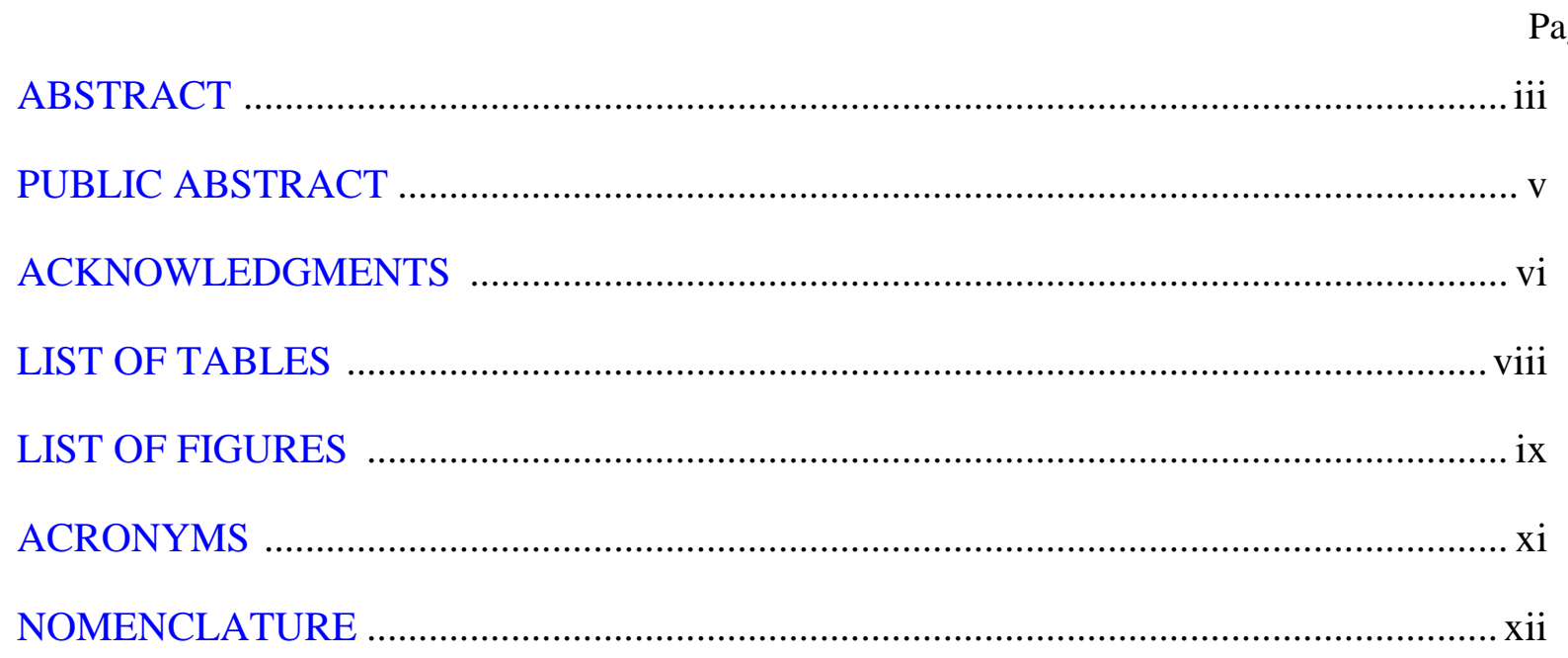

\section{CHAPTER}

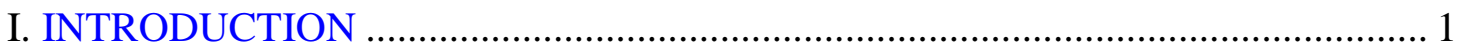

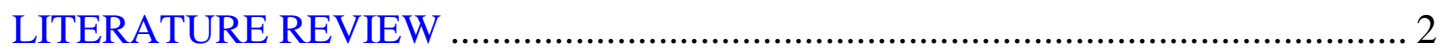

II. POTENTIAL CONTAMINATION EFFECTS OF BURNED ABS …………….... 7

GOX/ABS Plume Contamination Analysis …………….................................... 8

Exhaust Plume Contamination Measurements .................................................... 15

III. VACUUM CHAMBER TEST OF A FLIGHT WEIGHT 25-N THRUSTER ..... 16

Vacuum Chamber Performance Test Results …………………………………... 20

Thruster Performance Measurements ..................................................................... 21

IV. PLUME CONTAMINATION MEASUREMENTS …………………………..... 24

Effect of Plume Contamination on Photometer Illumination Level .......................... 27

Scanning Electron Microscope Analysis of Bridge Photometers ................................. 30

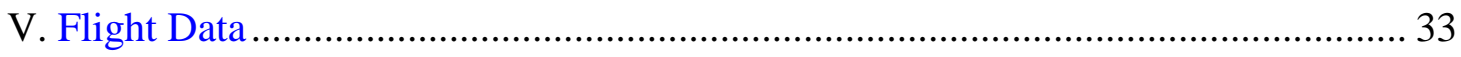

USIP Plume Contamination Test Results ................................................................ 37

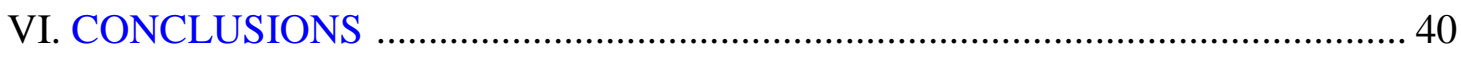

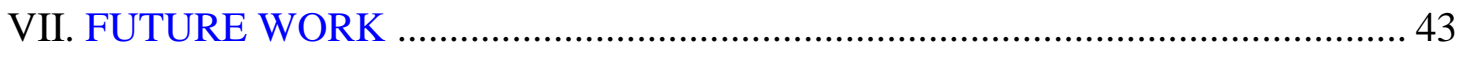

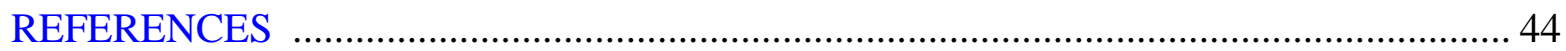




\section{LIST OF TABLES}

Table

Page

1 Hybrid Rocket Combustion Characteristics as a Function of Mass Flux ........11

2 ABS/GOX Hybrid Motor Test Geometry Summary …................................18

3 Summary of Ambient and Vacuum Thruster Performance Characterization

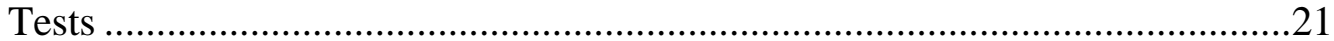




\section{LIST OF FIGURES}

Figure Page

1 Previously Tested Fuel Grain Prototypes ................................................. 1

2 Exhaust Plume Flow Characteristics and Flow Regimes Under Vacuum

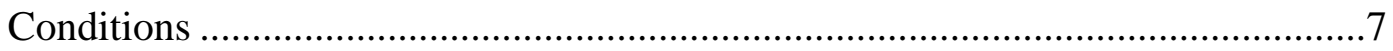

3 Characteristic Velocity and Flame Temperature for Various Pressure Levels

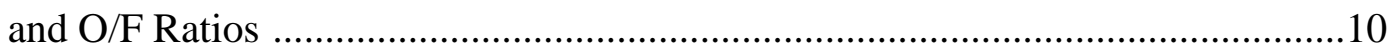

4 Characteristic Velocity and Species Mass Fraction of GOX/ABS contrasted

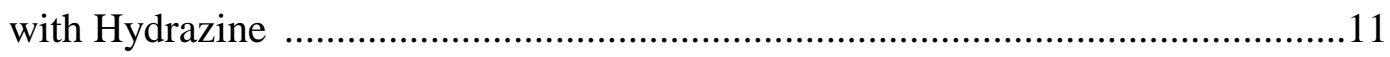

5 GOX/ABS Plume Species Concentration for various O/F Ratios ......................14

6 Photometer Sensor Design Layout and Prototype Units .....................................15

7 Response Properties of GL-55298 CdS Photoresistor .....................................16

8 Flight Weight Green Propellant Thruster .................................................19

9 Test Article Thrust Chamber Mechanical Schematic and Exploded View ..........19

10 25-N Thruster Mounted in Vacuum Chamber with Red LED Illumination .........20

11 25-N Thruster Mounted on Demo Test Rig stand with LED and

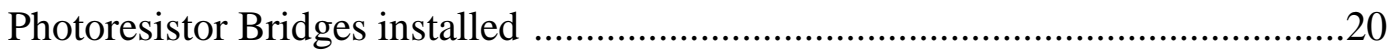

12 Time Histories of Pulsed Burns for Soft-Vacuum Conditions ...........................23

13 Comparison of Thruster Vacuum Exhaust Plumes for 2.064:1, and 9.5:1

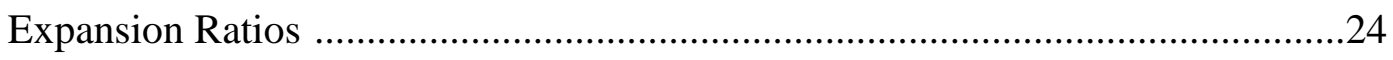

14 Typical Photometer Bridge Time History Output ..............................................25

15 Photo Resistor Bridge Time History Output from 10 Consecutive Thruster

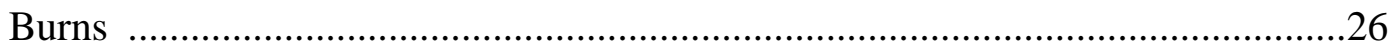

16 Photoresistor Bridge Peak Output Volts as a function of Burn Time (DTR) ......27

17 Photoresistor Bridge Time History Output from 10 Consecutive Thruster

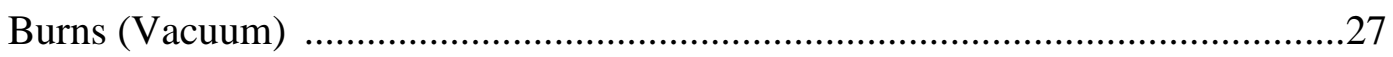

18 Photoresistor Bridge Time History Fraction Output from 10 Consecutive Thruster Burns .29

19 Photoresistor Bridge Time History Attenuation Output from 10 Consecutive Thruster Burns 
20 Photoresistor Bridge Time History Fraction Output from 10 Consecutive

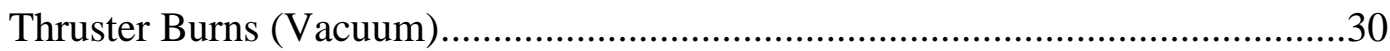

21 External Picture of the SEM Employed at USU ....................................................31

22 Internal Pictures of the SEM Employed at USU (Left: Top View, Right: Front View)

23 SEM Results for the Clean Glass piece (Left: Picture at 500X, Right: Chemical Composition) 32

24 SEM Results for the Bridge 1 Shield (Left: Picture at 500X, Right: Chemical Composition) 32

25 SEM Results for the Bridge 2 Shield (Left: Picture at 500X, Right: Chemical Composition) ..........................................33

26 Terrier Improved Malemute Rocket Launched for NASA USIP 2018 …................34

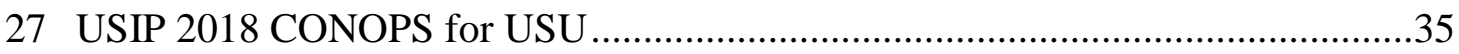

28 RockSat Deck and location of payload on the rocket .............................................35

29 USIP payload integration onto Terrier Improved Malemute ……………...............36

30 USU Assembly awaiting installation (Photoresistor and Wheatstone bridge hidden behind the thruster) .........................36

31 Fraction of Original Illumination (USIP Flight Data) .............................................37

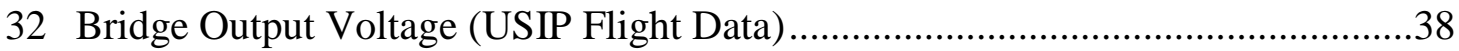

33 Chamber Pressure for both thrusters in USIP (Blue: Near, Black: Far) .................38

34 Mass flow for both thrusters in USIP ................................................................. 


\section{ACRONYMS}

\begin{tabular}{|c|c|}
\hline ABS & acrylonitrile butadiene styrene \\
\hline $\mathrm{CdS}$ & Cadmium Sulfide \\
\hline COTS & commercial off the shelf \\
\hline CEA & Chemical Equilibrium with Applications \\
\hline $\mathrm{CO}$ & Carbon Monoxide \\
\hline DSMC & Direct Simulation Monte Carlo \\
\hline DTR & Demo Test Rig \\
\hline GOX & gaseous oxygen \\
\hline $\mathrm{H}_{2} \mathrm{O}_{2}$ & hydrogen peroxide \\
\hline $\mathrm{HCN}$ & Hydrogen Cyanide \\
\hline HERO & Hazards of Electromagnetic Radiation to Ordnance \\
\hline LED & Light Emitting Diode \\
\hline $\mathrm{N}_{2} \mathrm{O}$ & nitrous oxide \\
\hline NASA & National Aeronautics and Space Administration \\
\hline MCVCM & Maximum Collected Volatile Condensable Material \\
\hline MSFC & Marshall Space Flight Center \\
\hline MOC & Method of Characteristics \\
\hline $\mathrm{O} / \mathrm{F}$ & oxidizer-to-fuel \\
\hline PRDL & Propulsion Research and Development Lab \\
\hline PRL & Propulsion Research Laboratory \\
\hline RGB & Red-Green-Blue \\
\hline SAN & styrene-acrylonitrile \\
\hline SEM & Scanning Electron Microscope \\
\hline TML & Total mass loss \\
\hline TRL & technology readiness level \\
\hline USAF & United States Air Force \\
\hline USIP & Undergraduate Student Instrument Project \\
\hline USU & Utah State University \\
\hline
\end{tabular}




\section{NOMENCLATURE}

$R \quad$ Resistance of Bridge Resistors $(1,2,3)$

lux Illumination level

$V_{e x} \quad$ Excitation Voltage of the Bridge

$V_{\text {out }}$ Output Voltage from the Bridge

$R_{x} \quad$ Resistance of the photoresistor 


\section{CHAPTER I}

\section{INTRODUCTION}

The Propulsion Research Laboratory at Utah State University recently developed and patented

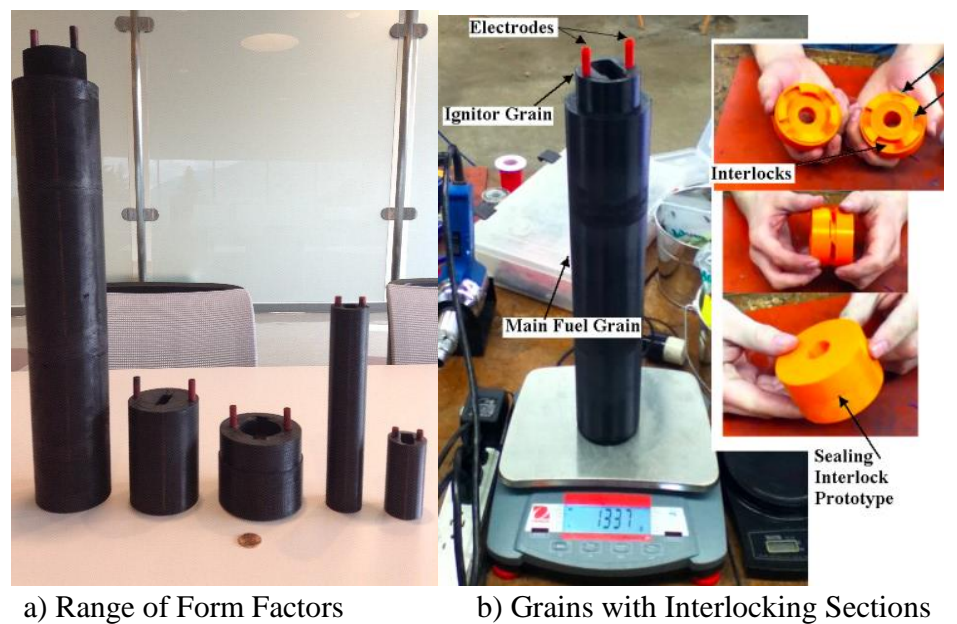

Fig. 1 Previously Tested Fuel Grain Prototypes arc-ignition system that overcomes multiple technical difficulties associated with hybrid rocket ignition systems. The USU-developed system allows hybrid motors to be started, stopped, and restarted with a high degree of reliability and require an ignition input less than 10 Joules. ${ }^{\mathrm{i}}$ The resulting non-pyrotechnic system and impervious to any associated Hazards of Electromagnetic Radiation to Ordnance (HERO). ${ }^{\text {ii }}$ This patented technology is derived from the unique electrical breakdown properties of 3-D printed acrylonitrile butadiene styrene (ABS), discovered serendipitously while investigating the thermodynamic performance of ABS as a hybrid rocket fuel. ${ }^{\text {iii }}$ Additive manufacturing is an essential feature of this configuration. Because additive manufacturing builds the specimen one layer at a time, 3D-printed ABS possesses unique electrical breakdown properties that have been exploited to allow for rapid on-demand system ignition. On demand ignition has been demonstrated using nitrous oxide $\left(\mathrm{N}_{2} \mathrm{O}\right)$, gaseous oxygen $(\mathrm{GOX})$, and hydrogen peroxide $\left(\mathrm{H}_{2} \mathrm{O}_{2}\right)$ as oxidizers. iv,v $^{\mathrm{v}}$

Multiple prototype devices with thrust values ranging from 4.5 to $900 \mathrm{~N}$ have been developed and tested. ${ }^{\text {vi }}$ Figure 1(a) shows the range of sizes and form factors that have been previously tested. 
Figure 1(b) shows the patented interlocking grain concept that allows large fuel grains to be printed from a relatively small printer. ${ }^{\mathrm{vii}}$ All units are capable of multiple restarts and can be operated in either continuous or pulse modes.

The GOX/ABS thruster has achieved specific impulse $\left(I_{s p}\right)$ values in excess of 220 seconds under ambient operating conditions, and greater than 280 seconds under soft-vacuum conditions. This $I_{s p}$ value exceeds the hydrazine performance level by more than $20 \%$. This performance enhancement is achieved by a comparably simple configuration layout with an inherently safe and environmentally sustainable system design. The current system offers the safety and environmental friendliness of a cold-gas system, but at a significantly higher performance level. This promising "green" hybrid-rocket alternative to hydrazine-based space propulsion systems currently lies at an intermediate state of development, with a technology readiness level (TRL)

estimated to be approximately between 4 and 5. This estimate was established using the USAF Technology Readiness Level (TRL) Assessment Tool. ${ }^{\text {viii }}$

\subsection{LITERATURE REVIEW}

It is well known that a serious complication due to space propulsion is the potential for adsorption of propellant effluents onto spacecraft surfaces. Plume contaminants can create multiple operational concerns including decreased power production from optical contaminants on solar array panels, and increased spacecraft temperatures due to contaminated thermal control surfaces. In an early study entitled, "Investigation of exhaust backflow from a simulated cluster of three wide-spaced rocket nozzles in a near-space environment,"ix NASA characterized the contamination primarily via temperature and pressure differences. This study also has a number of photographs showing the actual physical contamination, but none of these ever suggest the 
impact on an optical surface. The significance of this is despite the significant amount of literature on plume contamination most of this data is of limited value because they fail to identify how the optical properties are impacted by the contamination.

This dearth of data on plume effects on optical surfaces is also noted in the introductory section of a different NASA study "The effect of rocket plume contamination on the optical properties of transmitting and reflecting materials" ${ }^{\mathrm{x}}$, which noted it as follows:

More, recently, however, our endeavors have been directed towards investigating the effects of the local spacecraft environment (such as rocket plume impingement and waste gas venting) on optical properties. For long-term missions it is necessary to control the vehicle orientation by means of small attitude control thrusters. As a result, the exhaust products of these engines may present a serious contaminating source for such things as thermal control materials, optical sensors, and solar cell arrays, to name a few. These sources of contamination may or may not be of importance. The contamination effect is of concern only when the functional thermal or optical properties of a material of interest is measurably altered.

The biggest problem with studying the backflow plume contamination generated by various thrusters is that this effect doesn't occur with any significant effect in Earth's atmosphere. This makes experimental testing much more challenging because an environment like the vacuum of space must be simulated. In early research done by NASA in the 1960 's, ${ }^{\text {ix }}$ large vacuum chambers were used to generate a space-like environment because solving the equations specifically the Navier-Stokes and Boltzmann equations is extremely difficult. ${ }^{\mathrm{xi}}$ 
Both sets of equations are required because the internal flow properties of the chamber and the actual plume are best solved using the Navier-Stokes equations just like you would while in an atmosphere. However, the lack of particles in the vacuum of space means that once you leave the immediate plume regime there is insufficient fluid to apply the Navier-Stokes equations. Furthermore, while vacuum chambers are a good approximation of the space environment, they are not perfect. Even the best vacuum pumps can't maintain the pressure low enough to truly simulate the vacuum of space while burning a thruster inside. Since the vacuum pump is undoubtedly connected to only a few locations on the chamber, the pressure generated by the thruster will be drawn to those openings rather than dissipating in a more uniform fashion as it would in space. This means that any particulates generated by the thruster will also be biased towards travelling to those openings. The other major problem is that the true temperature of space is approximately 3 degrees Kelvin. Maintaining a vacuum chamber where the interior walls are at cryogenic temperatures is a massive feat, and as a result it is not commonly done. While space simulation chambers that are capable of maintaining temperatures of 3 Kelvin do exist, the costs of both obtaining liquid hydrogen and properly insulating the system from the extreme temperature are both extremely high. The effect is that in a vacuum chamber used for most rocket testing, the gases in the thruster plume can only cool to the ambient temperature of Earth. The inadequate cooling potentially results in reduced plume contamination as the gases do not solidify the way they might if the thruster had been fired in space.

The difficulties in properly simulating a space environment are the primary reason why most modern studies on backflow plume contamination run numerical simulations to obtain results. The simulations are then validated with actual spaceflight data. The Chinese Journal of 
Aeronautics has a detailed explanation of the reasons for this in the introductory section of

"Research on vacuum Plume and its effects" xii as follows:

Until now three kinds of methods are introduced to research the vacuum plume and its effects. The first one refers to the semi-experimental and analytical methods, which include the Simons method and MOC method. These methods have relatively high efficiency but low accuracy and are only suitable for simple cases. The second kind is the numerical simulation method. In the early 1960s, Bird proposed the DSMC method, $\underline{3}$ which directly simulates the physical phenomena described by the Boltzmann equation. Since the appearance of the DSMC method, it has been successfully applied to a wild range of high-altitude rarefied gas dynamics problems. The third one belongs to experimental study, which contains simulation experiments on the ground and flight experiments. Ground simulation experiments are often used to validate the numerical simulation programs and also used to measure small thruster plume parameters. Flight experiments can obtain the actual conditions of the plume. A flight experiment named SPIFEX was conducted to research plume effects by the U.S. space shuttle. However, the cost of flight experiment is too expensive.

The research of plume started in the 1960s. A lot of experimental researches were performed in recent years. With the advanced computation development, numerical simulation becomes a main tool for the plume study. The plume question could be understood more distinctly by combining experimental study and numerical simulation.

Many existing studies considered the plume contamination purely from quantitative dust particulate levels. There are numerous studies that document how much particular matter, often referred to as dust, their thruster produced from backflow contamination. As an example during a 
NASA-Boeing study titled "Thruster Plume Induced Contamination Measurements from the PIC and SPIFEX Flight Experiments" one of the plume contamination results from section 3.1 were characterized as follows: ${ }^{\text {iii }}$

To quantify the initial contaminant deposit, excluding the rapid evaporation effect, the initial deposit is calculated by summing the increase in frequency $(\Delta f)$ values for all 10 spikes. The decrease in frequency during the evaporation period is not included in this sum since it is related only to the evaporation of the deposited contaminant. The result is a total increase in frequency $(\Delta f)$ of $580 \mathrm{~Hz}$. This increase in frequency yields an initial mass deposition of $2.56 \mu \mathrm{g} / \mathrm{cm}^{2}$ for the ten seconds of total on-time, or an initial mass flux of $0.26 \mu \mathrm{g} / \mathrm{cm}^{2} \cdot \mathrm{s}$.

However, the impact of the dust could and probably does vary between propellants because the actual impact is based on the combustion byproducts of the thruster's plume. In general, more contamination equals greater degradation of performance, regardless of the chemical makeup of the particles. But since the combustion byproducts are not the same between different propellants, just analyzing the amount of dust doesn't reveal all of the useful information available. 
Chapter II

\section{POTENTIAL CONTAMINATION EFFECTS OF BURNED ABS}

$\mathrm{ABS}$ is an entirely new material for propulsion applications, and no database exists to describe the potential deleterious effects of the exhaust plume on spacecraft surfaces. In fact, the authors

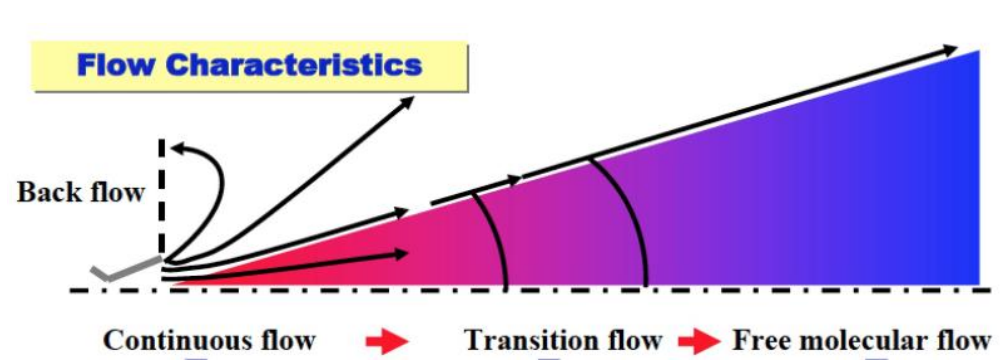

Fig. 2 Exhaust Plume Flow Characteristics and Flow Regimes Under Vacuum Conditions. could find no published literature presenting plume contamination measurements for any type of hybrid rocket. Additionally, this study goes step beyond existing studies by examining the composition of the

contaminants in addition to the total amount. Of particular concern is the potential optical degradation that plume contamination backflow would have on the surfaces of a spacecraft, and the optical effects will vary based on the amount of contamination and the specific chemical species deposited.

Generally, long lifetime requirement for spacecraft sensors mean that these exists a potential for years of exposure to contamination from on-orbit propulsion required for attitude control and orbit maintenance/corrections. These contamination effects can create multiple operational concerns; for example, the collection of molecules on solar arrays and thermal control surfaces can lead to decreased power production and increased spacecraft temperatures. As an example the Voyager 1 spacecraft, which employed several $0.9-\mathrm{N}$ hydrazine thrusters for trajectory adjustments, exhibited a $60 \%$ drop in the reaction-wheel torques resulting from solar cell contamination due to the plume effluent. ${ }^{\text {xiv }}$ 
Plume interactions generally results in three forms of contamination 1) condensation of exhaust species on baffles and optics, 2) pitting of optical surfaces, 3) film adsorption from the condensation, and 4) surface etching from acidic deposits. Contamination manifests itself on the sensor system by increased scatter, increased surface emissivity, and decreased signal to noise ratio. Figure 2 illustrates this effect where the aft-directed plume scatters at it expands rapidly into the vacuum, allowing a small fraction of the ejected particles to obtain lateral and even backscattered momentum, allowing interaction with spacecraft surfaces that are not directly in the path of the exhaust plume.

The experimental results to be presented will allow the effects of the GOX/ABS thruster exhaust plume contaminants on critical spacecraft components, including solar panels, antennae, and optical sensors, to be qualitatively and quantitatively assessed. These data can be used as check cases to verify existing particle and molecular contamination codes. To date no such plume contamination experiments have been performed for hybrid rocket systems. Development of this database is essential before the proposed systems can be considered for a ride-share spaceflight demonstration or for commercial development.

\subsection{GOX/ABS PLUME CHEMICAL ANALYSIS}

ABS is manufactured by co-polymerizing acrylonitrile and styrene to form styreneacrylonitrile (SAN). Butadiene gas is then dissolved into the SAN to create ABS. Typical ABS preparations contain $21 \%-27 \%$ acrylonitrile, $12 \%-25 \%$ butadiene, and $54 \%-63 \%$ styrene monomer fractions by mass. ${ }^{\mathrm{xv}}$ Acrylonitrile improves the overall chemical resistance, butadiene imparts impact resistance, and styrene supplies stiffness that allows good machinability. Butadiene also supplies the majority of the energy content to the polymer. Extruded ABS is a very stable material as shown by industrial sewer pipes that remain buried for decades with little degradation. 
NASA has tested the ABS plus® stock material used for the previously described thruster fuel grains $^{\mathrm{xvi}}$ and has classified the material as "low out gassing." In their series of tests, the material was heated to $125^{\circ} \mathrm{C}$ in a vacuum environment to drive off any volatile components. Total Mass Loss (TML) was measured at $0.63 \%$, and a Maximum Collected Volatile Condensable Material (CVCM) of $0.08 \%$. $^{\mathrm{xvii}}$

The tests to be summarized in the paper will use the commercially available Stratasys ABSPlus $340 ®$ as the feedstock for the additively manufactured fuel grains. The precise chemical formulation of this material is a closely held industrial secret of Stratasys Inc; however, the general monomer properties of ABS are publicly known, and some combustion toxicity analysis has been previously performed. ${ }^{\text {xviii }}$ Moreover, the general consensus from this literature survey is that since ABS can be created by a variety of processes that result in distinctively different monomer ratios and different resulting combustion by products.

In order to understand the types of exhaust product that may result from combustion of ABS in concentrated oxygen, the NASA-developed the equilibrium gas-chemistry code Chemical Equilibrium with Applications $(\mathrm{CEA})^{\mathrm{xix}, \mathrm{xx}}$ used to model the combustion products for the butadiene-rich ABS formulation tested by Whitmore and Peterson. ${ }^{\text {iii }}$ Here the assumed monomer ratio is $50 \%$ mole fraction of butadiene, $43 \%$ acrylonitrile, and $7 \%$ styrene. The "reduced" chemical formula corresponding to this mix ratio is $C_{3.85} H_{4.85} N_{0.43}$. Whitmore and Peterson ${ }^{\mathrm{iii}}$ calculated the enthalpy of formation of this formulation to $62.63 \mathrm{KJ} / \mathrm{mol}$ with a molecular weight of $57.07 \mathrm{~kg} / \mathrm{kg}$-mol. Figure 3 plots the resulting characteristic velocity $c^{*}$, flame temperature $T_{0}$, for pressure levels varying from 100 to 300 psia (690 to $2070 \mathrm{kPa}$ ). Best operating conditions for these propellant are slightly rich, with a peak $c^{*}$ near $1.6 \mathrm{O} / \mathrm{F}$ ratio. The stoichiometric $\mathrm{O} / \mathrm{F}$ ratio is 2.674, and best performance occurs between Equivalent Ratios, $\boldsymbol{\Phi}=1.6$ and 1.8 . 

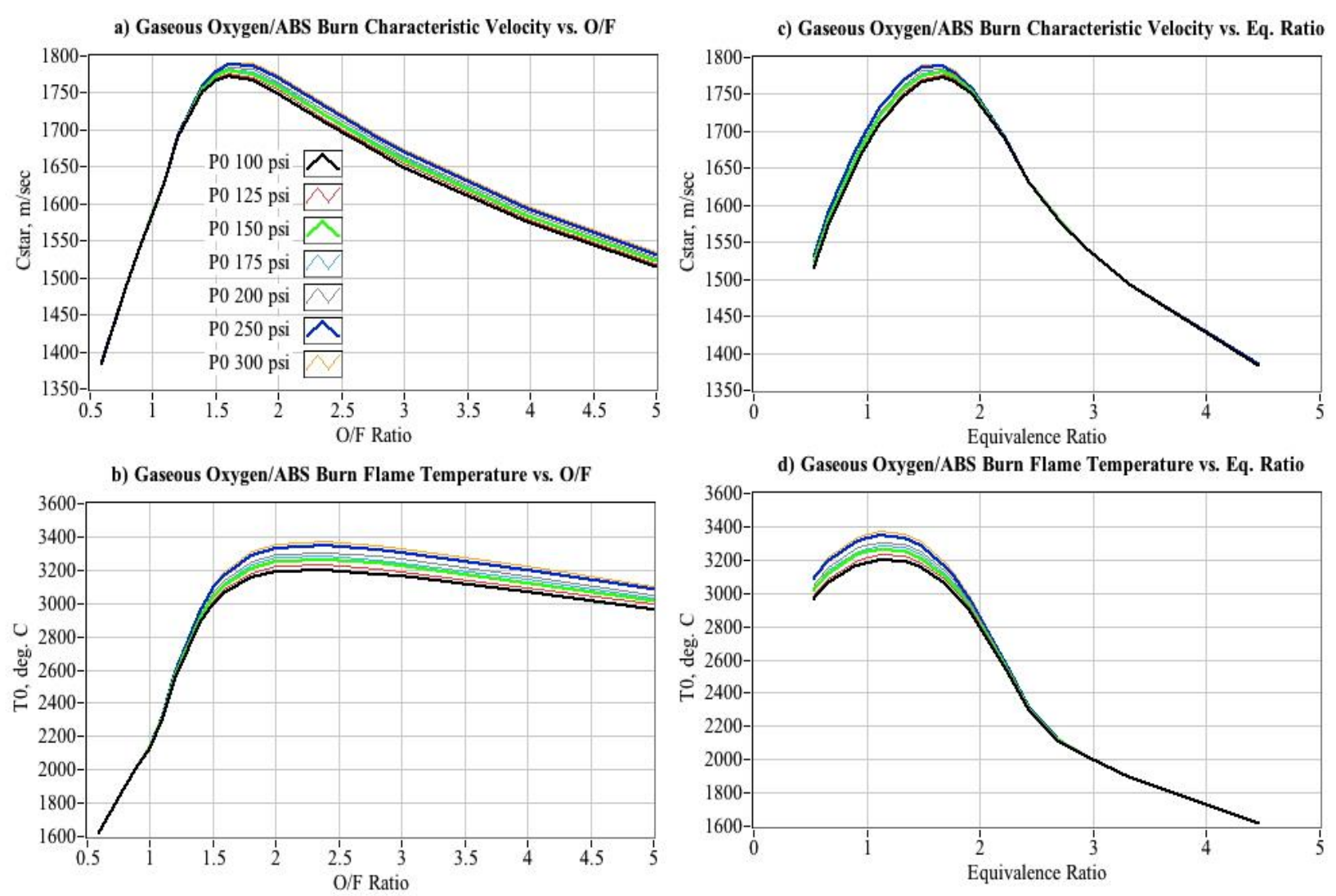

Fig. 3 Characteristic Velocity and Flame Temperature for Various Pressure Levels and O/F Ratios.

Table 1 shows the resulting $G O X / A B S$ exhaust plume mass concentrations for 8 different $\mathrm{O} / \mathrm{F}$ ratios with equivalence ratios ranging from fuel-rich $(\Phi>1)$ to lean $(\boldsymbol{\Phi}<1)$. Figure 3 compares the plume various mass concentrations graphically in a series of bar charts. The assumed combustion pressure was 150 psia, and corresponds to the approximate thrust levels of a smallspacecraft thruster. The specific combustion by-products produced from GOX ABS combustion are strongly dependent up the $\mathrm{O} / \mathrm{F}$ ratio. The primary exhaust products are carbon monoxide, carbon dioxide, water vapor, and gaseous hydrogen. No acidic or ozone depleting gases are produced. The principal gases responsible for any potential toxicity are $\mathrm{HCN}$ (hydrogen cyanide) and $\mathrm{CO}$ (carbon monoxide).

This analysis concludes that when the motor is operated in a fuel rich mode, the combustion by products tend to be more problematic, producing substantial mass fractions of $\mathrm{HCN}$ and $\mathrm{CO}$. 
Burning at low $\mathrm{O} / \mathrm{F}$ (higher equivalence ratios) also produces significant dirty, vaporized carbon $\mathrm{C}(\mathrm{gr})$; and should be avoided for flight operations. When the motor operates near the optimal O/F ratio between 1.5 and 2.0 (as the USU thruster has been designed), the combustion products for $G O X / A B S$ are relatively benign. Hydrogen cyanide gas does not result until equivalence ratios rise above approximately 2.3 .
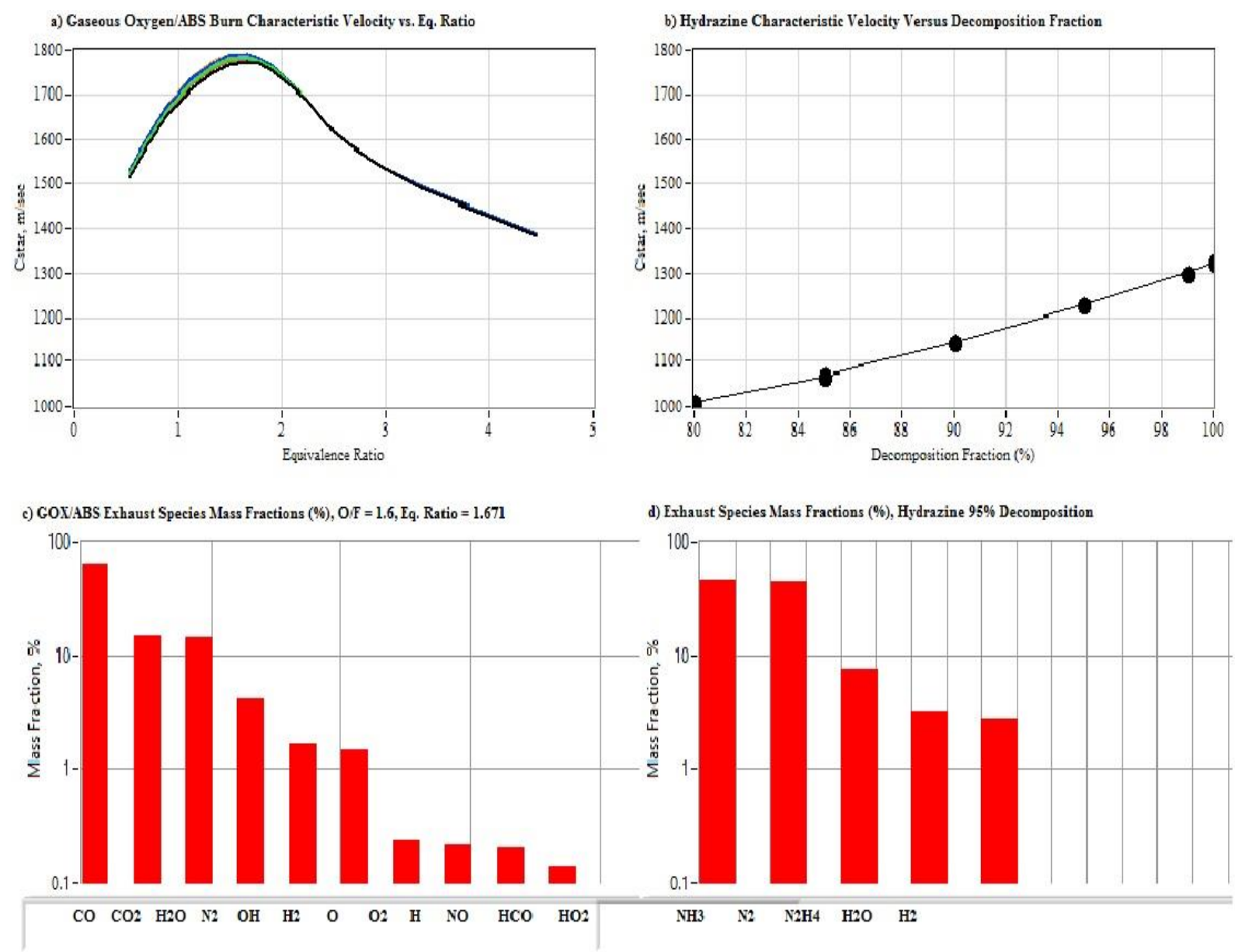

Fig. 4 Characteristic Velocity and Species Mass Fraction of GOX/ABS contrasted with Hydrazine.

As shown by Whitmore and Merkley ${ }^{\mathrm{xxi}}$ the current GOX/ABS thruster family feature $\mathrm{O} / \mathrm{F}$ ratios that vary from approximately 2.25 to slightly less than 1.30 across the burn lifetime. Per the results of Table 1 this burn profile generally results in "clean" exhaust by-products with $\mathrm{C}(\mathrm{gr})$, and carbon monoxide levels half of what is produced when traditional petroleum based hydrocarbons 
are burned. Figure 4 illustrates that GOX/ABS combustion has a significantly higher $\mathrm{c}^{*}$ than hydrazine does regardless of the Decomposition fraction of hydrazine. Figure 4 also indicates that most of the byproducts of GOX/ABS combustion will be gaseous when operating at or above the peak performance $\mathrm{O} / \mathrm{F}$ ratio of approximately 1.6 .

Most importantly, the data of Table 1, Figure 4, and Figure 5 demonstrate that GOX/ABS combustion does not produce ammonia decomposition products. As described previously the vast majority of operational spacecraft have relied on hydrazine as the main propellant. Highly fluent and condensable ammonia is an abundant by-product of hydrazine decomposition, and over the lifetime of a spacecraft can result in significant contamination of critical spacecraft surfaces. ${ }^{\text {xii }}$ The GOX-ABS hybrid does not produce highly-fluent by products. This, the potential for contamination is significantly reduced.

Table 1 Example GOX/ABS Propellant Combustion By-products at 150 Psia Combustion Pressure.

\begin{tabular}{lllllllllllllll}
\hline \multicolumn{10}{c}{ Chamber Pressure $=150$ psia, 0/F Ratio $=0.8000$, Equiv. Ratio $=3.3424$} \\
\hline Species: & $\mathrm{C} 0$ & $\mathrm{C}$ & $\mathrm{N} 2$ & $\mathrm{H} 2$ & $\mathrm{HCN}$ & $\mathrm{CH} 4$ & $\mathrm{C} 2 \mathrm{H} 2$ & $\mathrm{H} 2 \mathrm{C}$ & $\mathrm{CO} 2$ & $\mathrm{HNC}$ & $\mathrm{H}$ & $\mathrm{NH} 3$ & $\mathrm{CH} 3$ \\
\hline $\begin{array}{l}\text { Mass } \\
\text { Fraction: }\end{array}$ & 0.7776 & 0.1143 & 0.0573 & 0.0472 & 0.0023 & 0.0005 & 0.0003 & 0.0002 & 0.0001 & 0.0001 & 0.0000 & 0.0000 & 0.0000 \\
& & & & & & & & & & & & \\
\hline
\end{tabular}

Chamber Pressure $=150$ psia, O/F Ratio $=1.0000$, Equiv. Ratio $=2.67396$

\begin{tabular}{llllllllllllll}
\hline Species: & $\mathrm{CO}$ & $\mathrm{N} 2$ & $\mathrm{H} 2$ & $\mathrm{C}$ & $\mathrm{HCN}$ & $\mathrm{C} 2 \mathrm{H} 2$ & $\mathrm{HNC}$ & $\mathrm{CH} 4$ & $\mathrm{H} 2 \mathrm{O}$ & $\mathrm{CO} 2$ & $\mathrm{H}$ & $\mathrm{CH} 3$ & $\mathrm{C} 2 \mathrm{H} 4$ \\
\hline Mass & 0.8751 & 0.0502 & 0.0424 & 0.0261 & 0.0045 & 0.0010 & 0.0003 & 0.0002 & 0.0001 & 0.0001 & 0.0001 & 0.0000 & 0.0000 \\
Fraction: & & & & & & & & & & & & & \\
\hline
\end{tabular}

Chamber Pressure $=150$ psia, O/F Ratio $=1.2000$, Equiv. Ratio $=2.22829$

\begin{tabular}{llllllllllll}
\hline Species: & $\mathrm{CO}$ & $\mathrm{H} 2 \mathrm{O}$ & $\mathrm{N} 2$ & $\mathrm{CO} 2$ & $\mathrm{H} 2$ & $\mathrm{H}$ & $\mathrm{OH}$ & $\mathrm{NO}$ & $\mathrm{HCO}$ & 0 & $\mathrm{HCN}$ \\
\hline Mass & 0.8360 & 0.0484 & 0.0479 & 0.0340 & 0.0331 & 0.0004 & 0.0002 & 0.0000 & 0.0000 & 0.0000 & 0.0000 \\
Fraction: & & & & & & & & & & & \\
\hline
\end{tabular}


Chamber Pressure $=150$ psia, 0/F Ratio $=1.5000$, Equiv. Ratio $=1.78263$

\begin{tabular}{llllllllllll}
\hline Species: & $\mathrm{CO}$ & $\mathrm{H} 2 \mathrm{O}$ & $\mathrm{CO} 2$ & $\mathrm{~N} 2$ & $\mathrm{H} 2$ & $\mathrm{OH}$ & $\mathrm{H}$ & 0 & $\mathrm{NO}$ & 02 & $\mathrm{HCO}$
\end{tabular}

\begin{tabular}{llllllllllll}
\hline Mass & 0.6797 & 0.1301 & 0.1179 & 0.0418 & 0.0174 & 0.0091 & 0.0017 & 0.0009 & 0.0007 & 0.0006 & 0.0000
\end{tabular}

Fraction:

Chamber Pressure $=150$ psia, 0/F Ratio $=2.0000$, Equir. Ratio $=1.33698$

\begin{tabular}{llllllllllllll}
\hline Species: & $\mathrm{CO}$ & $\mathrm{CO} 2$ & $\mathrm{H} 2 \mathrm{O}$ & $\mathrm{OH}$ & $\mathrm{N} 2$ & $\mathrm{O} 2$ & $\mathrm{O}$ & $\mathrm{H} 2$ & $\mathrm{NO}$ & $\mathrm{H}$ & $\mathrm{H} 02$ & $\mathrm{HCO}$ & $\mathrm{N}$
\end{tabular}

\begin{tabular}{llllllllllllll}
\hline Mass & 0.4751 & 0.2418 & 0.1550 & 0.0415 & 0.0327 & 0.0268 & 0.0132 & 0.0066 & 0.0051 & 0.0021 & 0.0000 & 0.0000 & 0.0000
\end{tabular}
Fraction:

Chamber Pressure $=150$ psia, 0/F Ratio $=2.4000$, Equir. Ratio $=1.11415$

\begin{tabular}{llllllllllllll}
\hline Species: & $\mathrm{CO}$ & $\mathrm{CO} 2$ & $\mathrm{H} 2 \mathrm{O}$ & $\mathrm{O} 2$ & $\mathrm{OH}$ & $\mathrm{N} 2$ & $\mathrm{O}$ & $\mathrm{NO}$ & $\mathrm{H} 2$ & $\mathrm{H}$ & $\mathrm{H} 02$ & $\mathrm{~N}$ & $\mathrm{COOH}$
\end{tabular}
\begin{tabular}{llllllllllllll}
\hline Mass & 0.3654 & 0.2978 & 0.1472 & 0.0732 & 0.0531 & 0.0273 & 0.0225 & 0.0079 & 0.0039 & 0.0016 & 0.0000 & 0.0000 & 0.0000
\end{tabular} Fraction:

Chamber Pressure $=150$ psia, $0 / \mathrm{F}$ Ratio $=2.8000$, Equir. Ratio $=0.95498$

\begin{tabular}{llllllllllllll}
\hline Species: & $\mathrm{CO} 2$ & $\mathrm{CO}$ & $\mathrm{H} 2 \mathrm{O}$ & $\mathrm{02}$ & $\mathrm{OH}$ & $\mathrm{O}$ & $\mathrm{N} 2$ & $\mathrm{~N} 0$ & $\mathrm{H} 2$ & $\mathrm{H}$ & $\mathrm{H} 02$ & $\mathrm{NO2}$ & $\mathrm{N}$ \\
\hline Mass & 0.3301 & 0.2865 & 0.1372 & 0.1259 & 0.0562 & 0.0275 & 0.0233 & 0.0094 & 0.0026 & 0.0012 & 0.0001 & 0.0000 & 0.0000 \\
Fraction: & & & & & & & & & & & & & \\
\hline
\end{tabular}

Chamber Pressure $=150$ psia, 0/F Ratio $=4.0000$, Equir. Ratio $=0.66848$

\begin{tabular}{llllllllllllll}
\hline Species: & $\mathrm{CO} 2$ & 02 & $\mathrm{CO}$ & $\mathrm{H} 2 \mathrm{O}$ & $\mathrm{OH}$ & $\mathrm{O}$ & $\mathrm{N} 2$ & $\mathrm{NO}$ & $\mathrm{H} 2$ & $\mathrm{H}$ & $\mathrm{H} 02$ & $\mathrm{NO} 2$ & $\mathrm{H} 2 \mathrm{O} 2$
\end{tabular}

\begin{tabular}{llllllllllllll}
\hline Mass & 0.3619 & 0.2723 & 0.1471 & 0.1124 & 0.0498 & 0.0283 & 0.0162 & 0.0104 & 0.0010 & 0.0006 & 0.0001 & 0.0000 & 0.0000
\end{tabular} Fraction: 

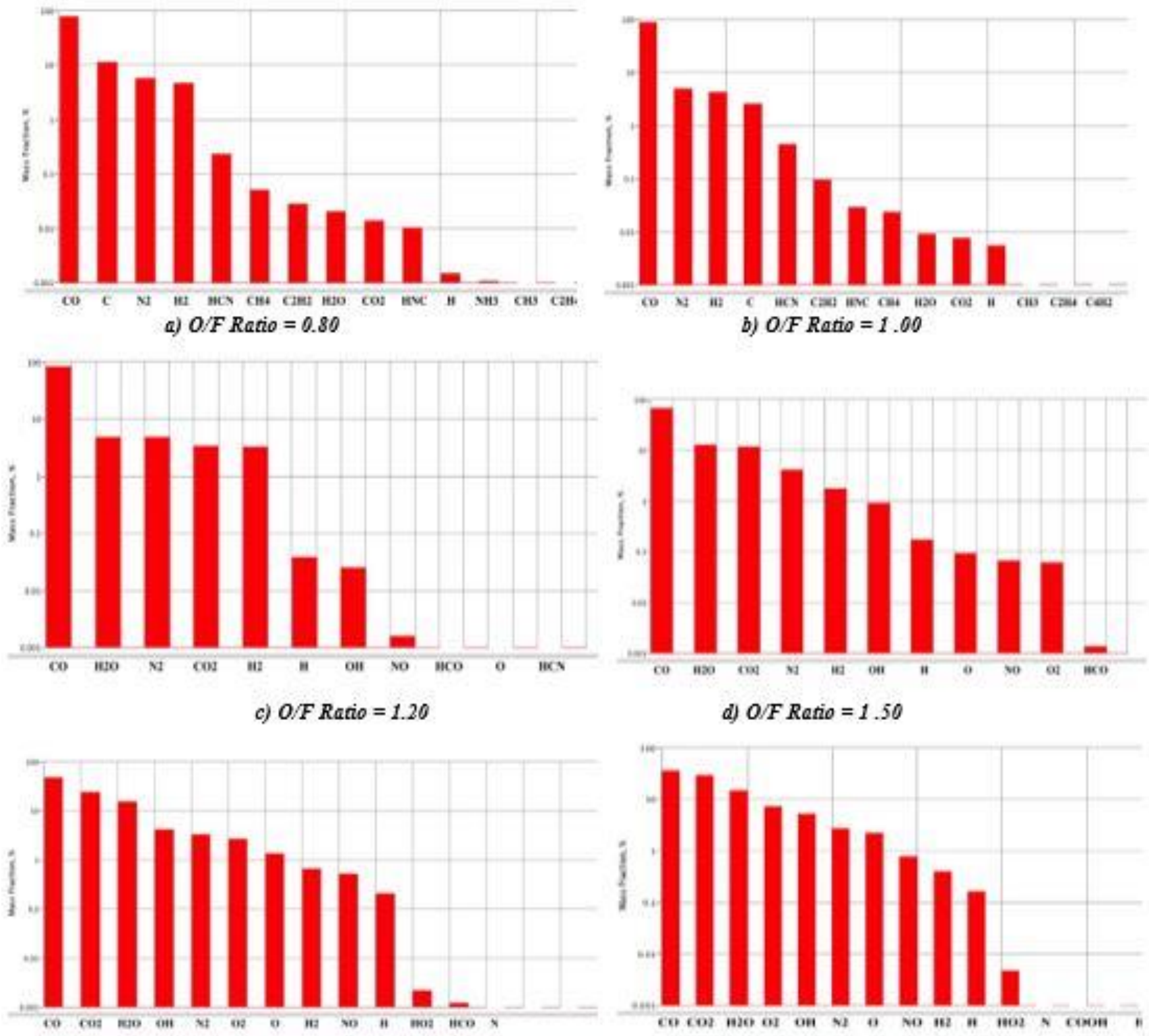

e) $O / F$ Ratio $=2.00$

f) $O / F$ Ratio $=2.40$
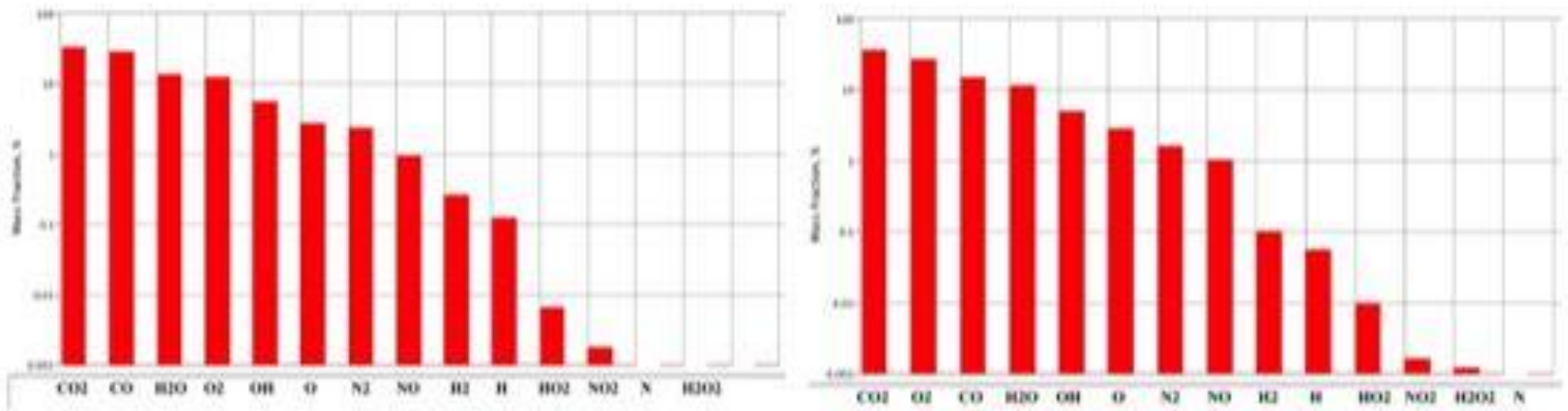

g) $O / F$ Ratio $=2.80$

h) $O / F$ Ratio $=4.0$

Fig. 5 GOX/ABS Plume Species Concentration for Various O/F Ratios. 


\subsection{EXHAUST PLUME CONTAMINATION MEASUREMENTS}

The contamination measurements to be presented in this paper are based on a photometer design previously developed for the USAF ESEX flight test experiment. ${ }^{\text {xiii }}$ Figure 6(a) shows the sensor concept where a PC-board mounted light-sensitive cadmium-sulfide $(C d S)$ photo-resistor ${ }^{1}$ receives illumination behind a quartz glass window that is intended to simulate spacecraft optical surfaces. The sensor glass surface footprint measures approximately one square inch. Figure $6 \mathrm{~b}$ shows the prototype bridge sensor and the accompanying LED light source to be described later in this section. The change of resistance of the $C d S$ photo-resistor is converted to a voltage output signal using a simple Wheatstone bridge circuit.

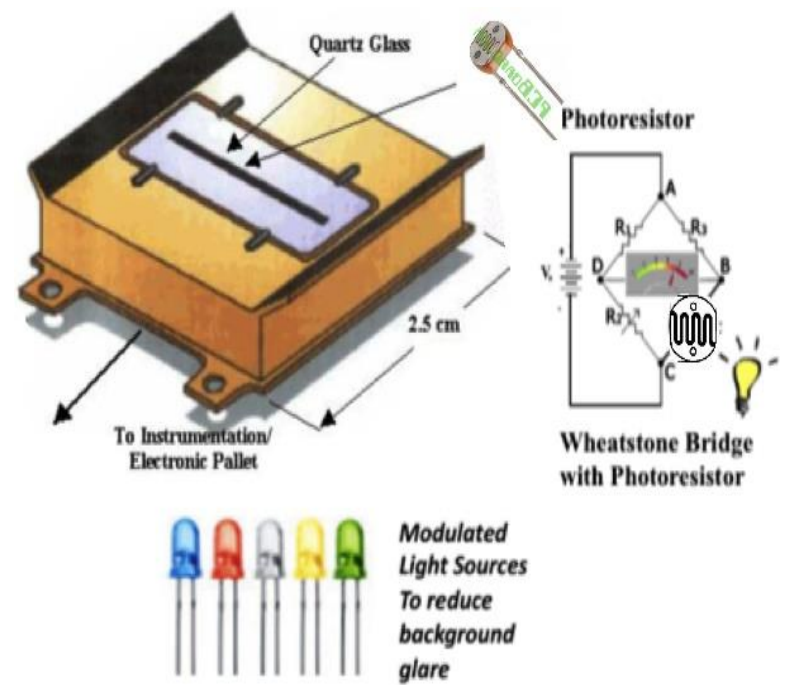

a) Sensor Design

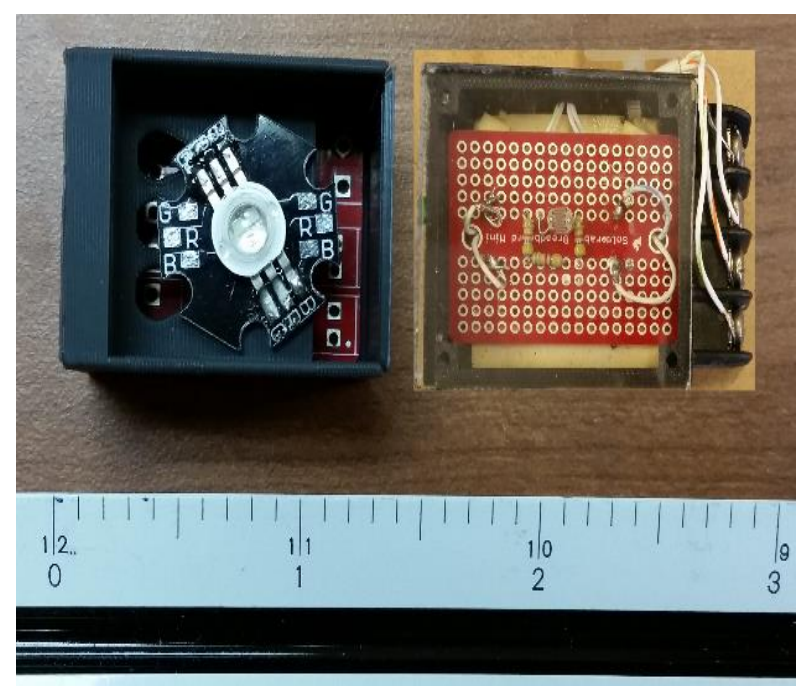

b) Prototype Units

Fig. 6 Photometer Sensor Design Layout and Prototype Units.

\footnotetext{
${ }^{1}$ Anon, "CdS Photoconductive Cells, GL55298, https://cdn.sparkfun.com/datasheets/Sensors/LightImaging/SEN-09088.pdf, [Cited 3-22-2107].
} 


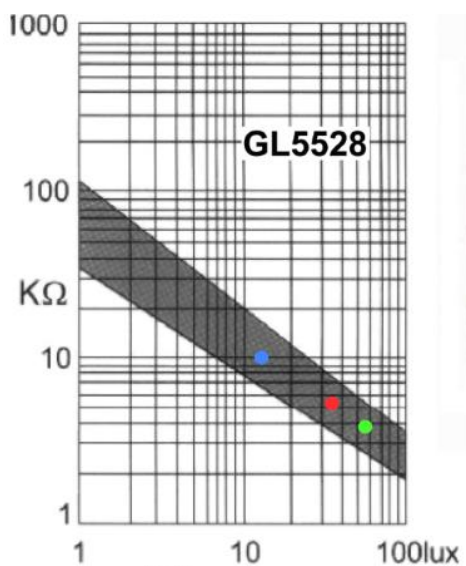

a) Illuminance

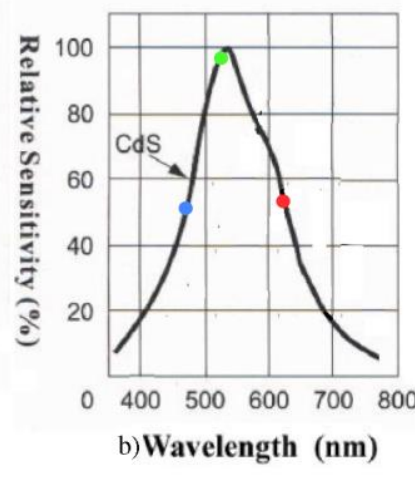

Fig. 7 Response Properties of GL-55298 CdS Photoresistor.

Figure 7(a) plots the photoresistance of the GL-55298 photoresistor as a function of the illumination level, and Figure 7(b) plots the spectral response. Although the best response level is near the green wavelength at approximately $620 \mathrm{~nm}$, the response of the resistor is good over the entire visible light spectrum.

A three-color high intensity light emitting diode (LED) is used to provide a known illumination source. The high-powered $\mathrm{LED}^{2}$ outputs three different with emission frequencies $630 \mathrm{~nm}$ (Red), 460 (Blue), and $520 \mathrm{~nm}$ (Green) in the visible light spectrum. The corresponding RGB luminous flux levels are 35, 13, and $57 \mathrm{~J} / \mathrm{sec}$ (lumens). These flux levels are plotted on the photo response chart of Figure 7. The light source is modulated at a set frequency so that the resulting measurements can be band passed filtered using Fourier transform techniques eliminate spurious light contamination. ${ }^{\text {xiv }}$

\section{Chapter III}

\section{VACUUM CHAMBER TESTS OF A FLIGHT WEIGHT 25-N THRUSTER.}

A prototype 25-N flight weight thruster system was vacuum tested during the summer of 2016 in the NASA Marshall Space Flight Center's (MSFC) Propulsion Research and Development Laboratory (PRDL). Test objectives included 1) demonstration of reliable multiple restart

\footnotetext{
${ }^{2}$ Anon, LED Model YSH-FRGBB-1A, China-Yung SUN LED Technology Co. LTD, https://www.sparkfun.com/datasheets/Components/LED/COM-08718-datasheet.pdf.
} 
capability under near vacuum conditions, 2) characterization of the vacuum specific impulse with a high expansion ratio nozzle, 3) characterization of the system startup time under vacuum conditions, 4) identify any possible corona discharge effects due to the high-ignition voltage at low operating pressure levels, and 5) obtain preliminary plume contamination measurements using the sensor package described in the previous section.

Prior to the vacuum tests this thruster has been previously well-characterized by a series of static-firings under ambient pressure conditions at the Utah State Propulsion Research Laboratory. ${ }^{\mathrm{xxv}}$ For the vacuum tests a separate non-flight weight feed system delivered the oxidizer (GOX) to the thrust chamber. The vacuum chamber altitude system consists of a vacuum chamber roughly $4.5 \mathrm{ft}^{3}$ in volume that is evacuated by a rotary vacuum pump. The pump discharges outside of the building into a stainless steel drum.

Table 2 lists the key motor component parameters. The test article features 1) a thrust chamber, 2) phenolic line, 3) motor cap with integral oxidizer injector, 4) fuel grain with embedded electrodes, 5) graphite nozzle, and 6) nozzle retainer. The rocket nozzle, nozzle retainer, and injector cap were manufactured by Utah State University, and have been previously tested and well-characterized under ambient pressure operating conditions. The rocket thrust chamber is constructed from 6061-T6 high-temperature aluminum, and was procured commercially from Cesaroni Inc. as commercial off-the-shelf (COTS) equipment. The phenolic liner was purchased from an on-line retail distributer. Both low (2.064:1) and optimal (9.5:1) expansion ratio nozzles were evaluated. 
Table 2 Motor Geometry Parameter Specifications.

\begin{tabular}{|c|c|c|c|c|}
\hline Parameter & Injector & & Single Port $-0.127 \mathrm{~cm}$ & Diameter \\
\hline Fuel Grain & Diameter: $3.168 \mathrm{~cm}$ & Length: $6.850 \mathrm{~cm}$ & $\begin{array}{l}\text { Initial Weight: } \\
50.0 \mathrm{~g}\end{array}$ & $\begin{array}{l}\text { Initial Port Diameter: } \\
0.625 \mathrm{~cm}\end{array}$ \\
\hline Motor Case & Diameter: $3.8 \mathrm{~cm}$ & Length: $13.8 \mathrm{~cm}$ & Wall Thickness: $1.5 \mathrm{~m}$ & \\
\hline $\begin{array}{l}\text { Low Expansion } \\
\text { Ratio Nozzle }\end{array}$ & $\begin{array}{l}\text { Initial Throat Diameter: } \\
0.401 \mathrm{~cm}\end{array}$ & $\begin{array}{l}\text { Exit Diameter: } \\
0.583 \mathrm{~cm}\end{array}$ & $\begin{array}{l}\text { Ambient Tests } \\
\text { Initial Expansion } \\
\text { Ratio: } 2.1: 1\end{array}$ & $\begin{array}{l}\text { Nozzle Exit Angle: } 5.0 \\
\text { deg. }\end{array}$ \\
\hline $\begin{array}{l}\text { High Expansion } \\
\text { Ratio Nozzle }\end{array}$ & $\begin{array}{l}\text { Initial Throat Diameter: } \\
0.401 \mathrm{~cm}\end{array}$ & $\begin{array}{l}\text { Exit Diameter: } \\
1.215 \mathrm{~cm}\end{array}$ & $\begin{array}{l}\text { Vacuum Tests Initial } \\
\text { Expansion Ratio: } \\
9.5: 1\end{array}$ & $\begin{array}{l}\text { Nozzle Exit Angle: } \\
20.0 \text { deg. }\end{array}$ \\
\hline
\end{tabular}

Figure 8(a) shows the additively-manufactured ABS fuel grain prior to testing. The printed fuel grains were fabricated from Stratasys ABSplus-340® feed-stock. Figure 8(b) shows the thruster during a 1-second pulse-firing. Figure 9 shows the thrust chamber schematic. Figure 10 shows the thruster installed in the vacuum chamber and illuminated by the red-LED. The details of the thrust stand instrumentation are also shown. The plume contamination sensor is mounted on the lower rail of the test sled rail, just upstream of the nozzle exit plane, and the LED is mounted onto the opposite chamber wall shining directly down onto the photometer. Arrows point to the LED and plume sensor locations. Figure 11 shows the thruster installed on the Demo Test Rig cart with the LED and Photoresistor bridges installed. It also has a piece of the space shuttle tile mounted to simulate backflow from vacuum conditions. 


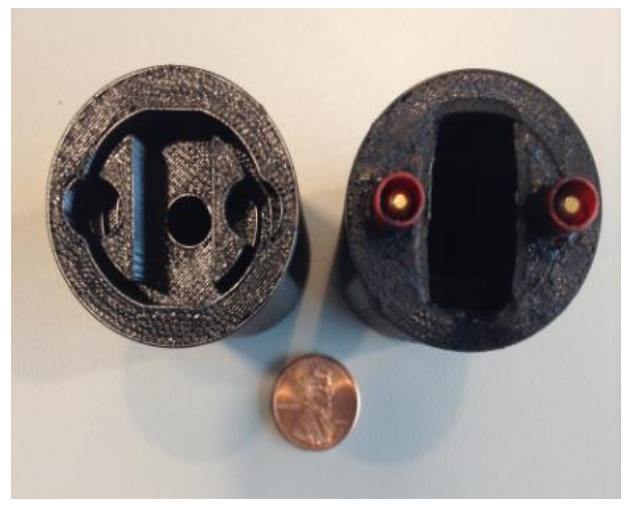

a) Printed Fuel Grain with Electrodes

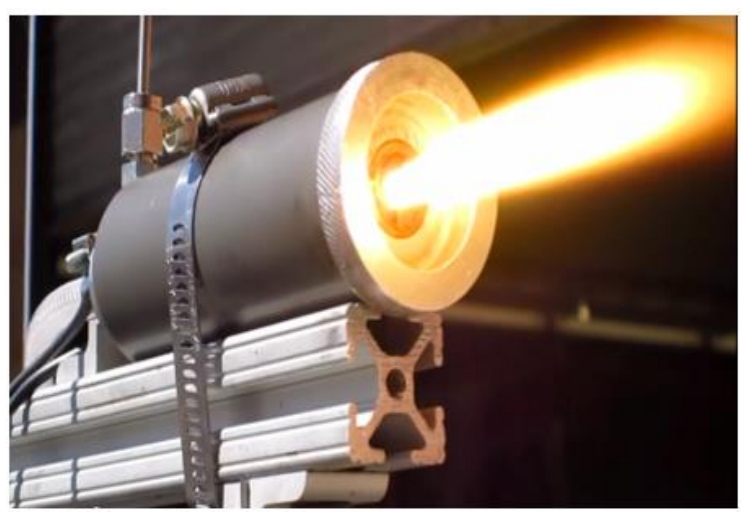

b) Static Test Firing

Fig. 8 Flight-Weight Green Propellant Thruster.
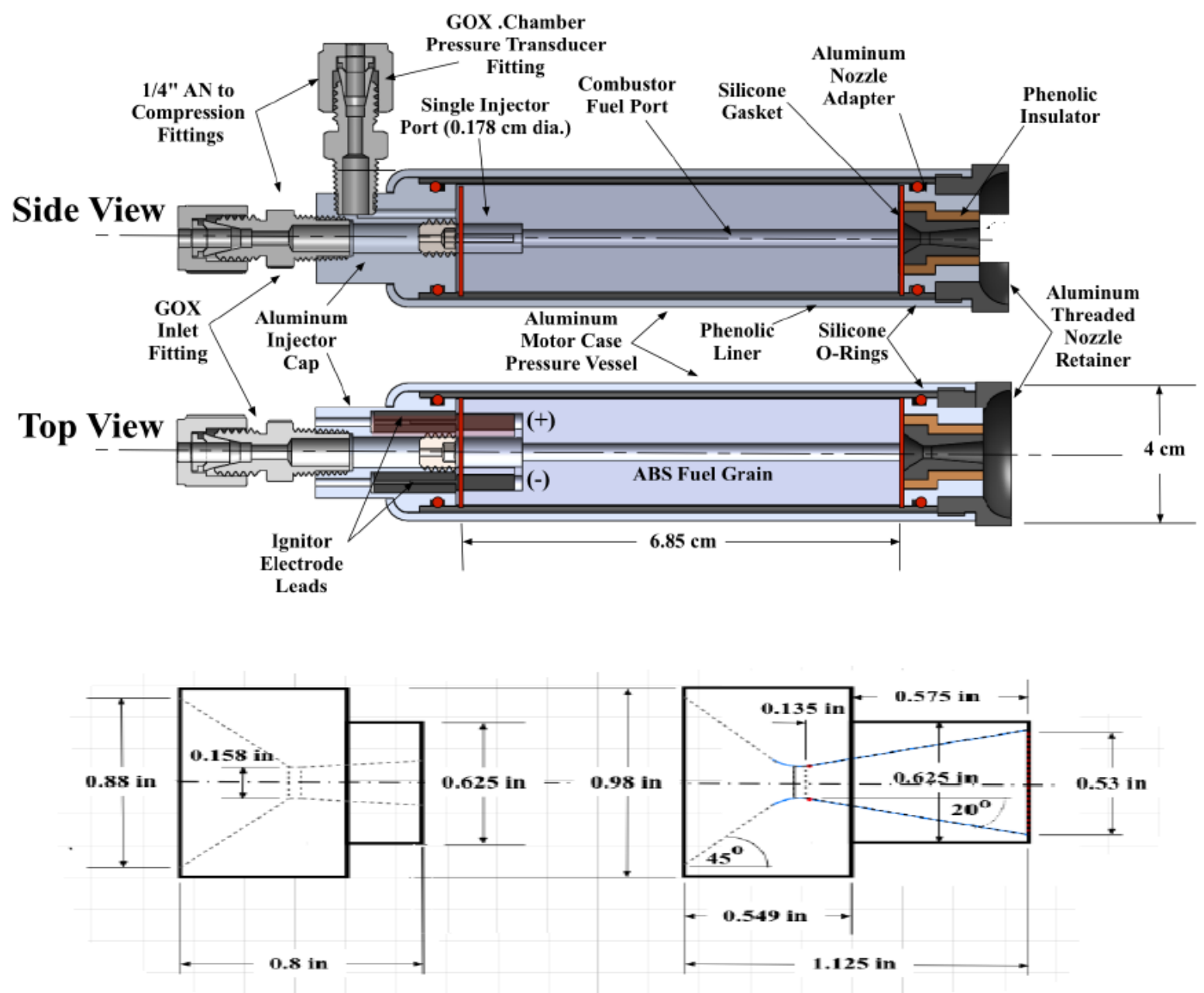

Fig. 9 Test Article Thrust Chamber Mechanical Schematic and Exploded View. 

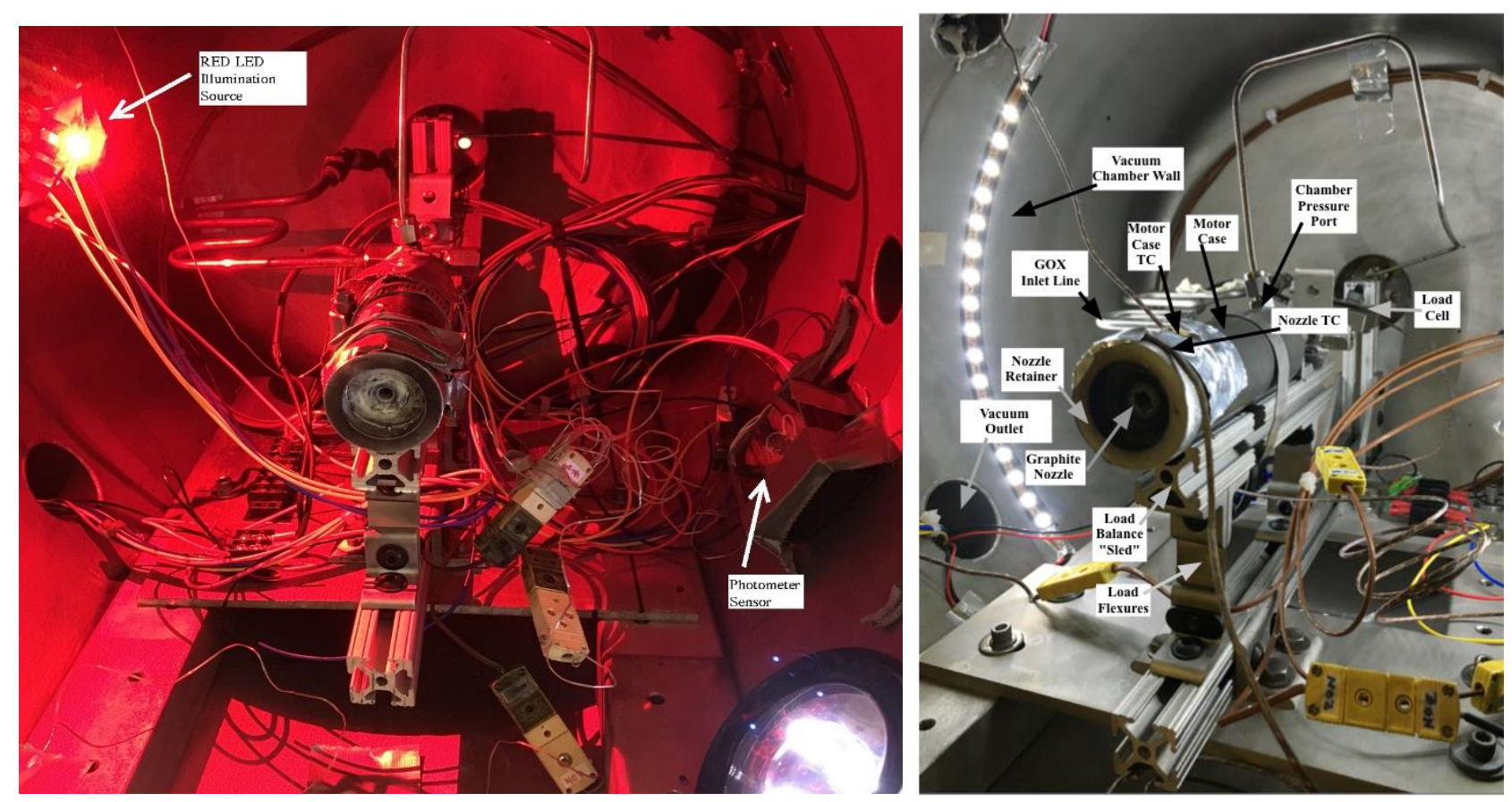

Fig. 10 25-N Thruster Mounted in Vacuum Chamber with Red LED Illumination.

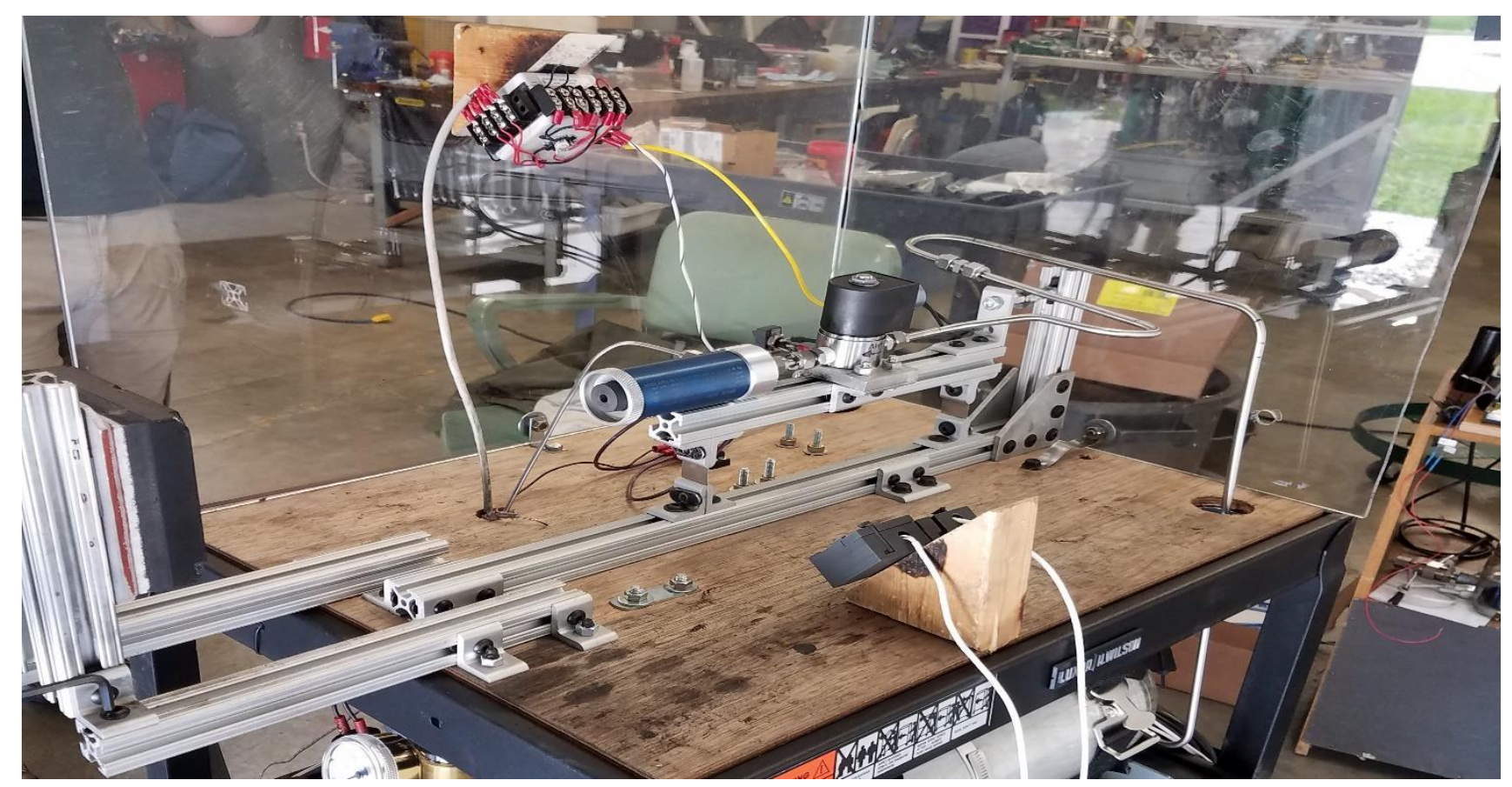

Fig. 11 25-N Thruster Mounted on Demo Test Rig stand with LED and Photometers installed. 


\subsection{VACUUM CHAMBER PERFORMANCE TEST RESULTS}

Table 3 summarizes the results from both the ambient and vacuum motor characterization tests. As mentioned previously, before the vacuum testing campaign, this thruster had been previously characterized under ambient test conditions in the USU Propulsion Research Laboratory, Logan Utah using a near-optimal nozzle expansion ratio of $2.064: 1{ }^{3}$ Whitmore and Mathias ${ }^{\mathrm{xxvi}}$ give a complete description of the test stand and the instrumentation system used to collect the ambient test measurements. The MSFC vacuum tests were repeated with the 2.064:1 nozzle and a nearoptimal nozzle with a higher an expansion ratio of 9.5:1. The mean $I_{s p}$ for the ambient tests was approximately 213 seconds, with a burn-to-burn standard-deviation of \pm 7.4 seconds. As expected, when compared to the ambient pressure tests, the vacuum thrust and $I_{s p}$ levels are noticeably higher, with $235.3 \pm 7.5$ seconds being achieved by the low $(2.064: 1)$ expansion ration nozzle and 280.0+7.3 seconds being achieved with the high (9.5:1) expansion ratio nozzle. This $I_{s p}$ increase is clearly a result of the reduced backpressure and the higher expansion ratio (9.5:1) nozzle.

Table 3 Summary of Ambient and Vacuum Thruster Performance Characterization Tests.

\begin{tabular}{|c|c|c|c|c|c|c|c|c|c|}
\hline $\begin{array}{l}\text { Motor } \\
\text { Configuration }\end{array}$ & $\begin{array}{l}\text { \# of } \\
\text { Burns }\end{array}$ & $P c$ & $F$ & $F_{\max }$ & $I_{s p}$ & $\begin{array}{l}\text { Ignition } \\
\text { Energy }\end{array}$ & $\tau_{\text {rise }}$ & $\begin{array}{l}\mathrm{O} / \mathrm{F} \\
\text { Ratio }\end{array}$ & $\begin{array}{l}\text { Combusti } \\
\text { on } \\
\text { Efficiency } \\
, \eta^{*}\end{array}$ \\
\hline $\begin{array}{l}2.064: 1 \text { initial } \\
\varepsilon, \text { Ambient } \\
\text { Conditions }\end{array}$ & 8 & $\begin{array}{l}155.16 \\
+-4.88 \\
\text { psia }\end{array}$ & $\begin{array}{l}20.49 \\
\pm 1.16 \mathrm{~N}\end{array}$ & $\begin{array}{l}20.96 \\
\pm 0.49 \mathrm{~N}\end{array}$ & $\begin{array}{r}212.84 \\
\pm 7.41 \mathrm{~s}\end{array}$ & $\begin{array}{l}1.67 \\
\pm 0.23 \mathrm{~J}\end{array}$ & $\begin{array}{l}214.0 \\
\pm 46.0 \mathrm{~ms}\end{array}$ & N/A & $95 \%$ \\
\hline $\begin{array}{l}2.064: 1 \text { initial } \\
\varepsilon, \text { Vacuum } \\
\text { Conditions }\end{array}$ & 10 & $\begin{array}{l}180.01 \\
\pm 5.75 \\
\text { psia }\end{array}$ & $\begin{array}{l}24.65 \pm \\
1.06 \mathrm{~N}\end{array}$ & $\begin{array}{l}26.58 \\
\pm 0.89 \mathrm{~N}\end{array}$ & $\begin{array}{r}235.27 \\
\pm 7.57 \mathrm{~s}\end{array}$ & $\begin{array}{l}1.38 \\
\pm 1.01 \mathrm{~J}\end{array}$ & $\begin{array}{l}132.5 \\
+30.9 \mathrm{~ms}\end{array}$ & $\begin{array}{l}2.37 \\
+0.35\end{array}$ & $\begin{array}{l}95.5 \% \\
+1.70 \%\end{array}$ \\
\hline $\begin{array}{l}\text { 9.5:1 initial } \varepsilon, \\
\text { Vacuum } \\
\text { Conditions }\end{array}$ & 20 & $\begin{array}{l}183.92 \\
\pm 9.63 \\
\text { psia }\end{array}$ & $\begin{array}{l}30.84 \pm \\
1.36 \mathrm{~N}\end{array}$ & $\begin{array}{l}32.98 \\
\pm 0.92 \mathrm{~N}\end{array}$ & $\begin{array}{r}280.01 \\
\pm 7.23 \mathrm{~s}\end{array}$ & $\begin{array}{l}1.63 \\
\pm 0.43 \mathrm{~J}\end{array}$ & $\begin{array}{l}122.5 \\
+44.3 \mathrm{~ms}\end{array}$ & $\begin{array}{l}1.94 \\
+0.46\end{array}$ & $\begin{array}{l}94.1 \% \\
+0.96 \%\end{array}$ \\
\hline
\end{tabular}

\footnotetext{
${ }^{3}$ These tests were performed in the Utah State Propulsion Test Laboratory Test Cell at an elevation of approximately 1400 meters (4600 ft.) altitude. Nominal atmospheric pressure at this altitude is approximately $85.6 \mathrm{kPa}(12.415 \mathrm{psia})$.
} 


\subsection{THRUSTER PERFORMANCE MEASUREMENTS}

Figure 12 plots a typical 4-pulse burn time history from the vacuum tests in this test series the 1 -second burns were followed with a 10 second recovery time in order to ensure that the vacuum chamber returned to near its minimum pressure level between each burn. Plotted are Plotted are the a) thrust as measured by the load cell and calculated from chamber pressure, b) chamber, nozzle exit, and vacuum chamber pressure, c) nozzle exit, oxidizer and fuel mass flow, d) specific impulse as calculated from the thrust, chamber pressure, and total mass flow, e) ignitor input voltage, and f) ignitor input power and total input energy. With the thruster firing, the vacuum systems were able to maintain a mean chamber pressure of approximately 0.15 atmospheres. This value corresponds to a vacuum pressure of approximately 650 torr below one standard atmosphere, and are thus considered to be "soft vacuum" conditions.

For each configuration the 4-pulse burn tests were repeated 5 times and data from a total of 20 successful 1-second burns were collected. The ensemble mean thrust level is $30.85 \mathrm{~N}$ with a standard deviation of $\pm 1.96 \mathrm{~N}$. At the $95 \%$ confidence level the estimated error range for the ensemble mean thrust is $\pm 0.88 \mathrm{~N}$. The ensemble mean $I_{s p}$ is $280.0 \mathrm{sec}$ with a sample standard deviation of \pm 8.4 seconds. At the $95 \%$ confidence level the estimated error range for the ensemble mean $I_{s p}$ is \pm 3.8 seconds. The ensemble mean ignition power drawn is 1.38 watts with a sample standard deviation of \pm 0.46 watts. At the $95 \%$ confidence level the estimated error in the mean ignition energy is \pm 0.21 watts. The ensemble mean rise time for the vacuum tests is 133 milliseconds with a standard deviation of $\pm 20 \mathrm{~ms}$. At the $95 \%$ confidence level the estimated error range for the ignition rise time is $\pm 8.9 \mathrm{~ms}$. This rise time is approximately $70 \%$ of the value measured during the ambient pressure tests. Most likely, the nozzle throat chokes sooner under vacuum conditions, thus allowing the chamber pressure to build up faster. 
Figure 13 shows photographic images taken of the exhaust plume for the low $(2.064: 1)$ and higher (9.5:1) expansion ratio nozzles during the vacuum tests. Image (a) shows the "splayed" exhaust plume that is characteristic of an under expanded nozzle. With the low expansion ratio, the exit pressure is substantially higher than the background pressure in the vacuum chamber, and the plume expands immediately aft of the nozzle exit plane. Image (b) taken with the near-optimal higher-expansion ratio nozzle shows a more uniform exhaust plume with only a slight expansion of the plume aft of the nozzle exit plane.

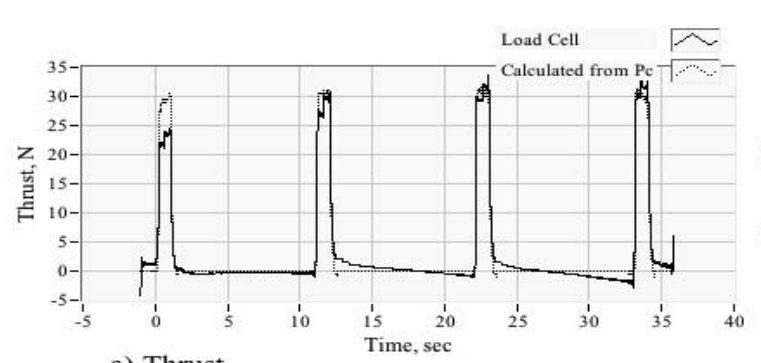

a) Thrust

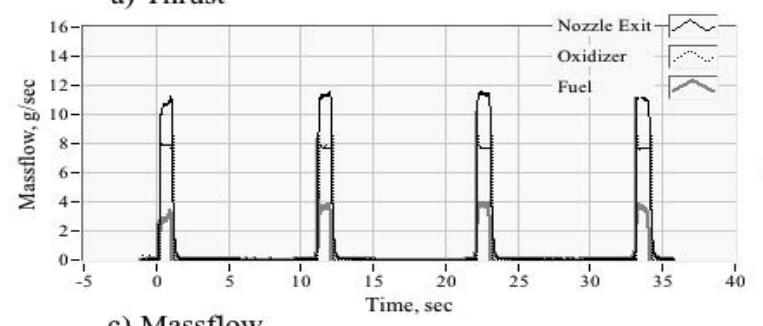

c) Massflow

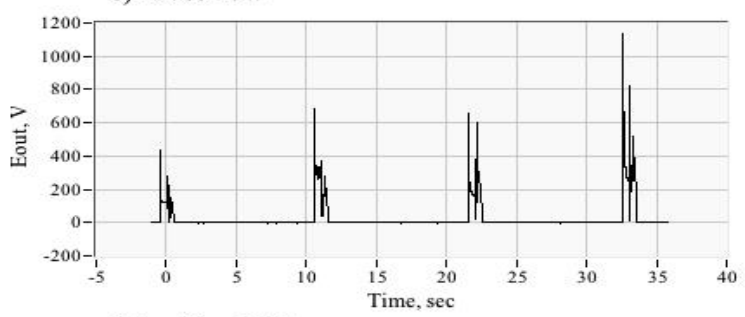

e) Ignition Voltage

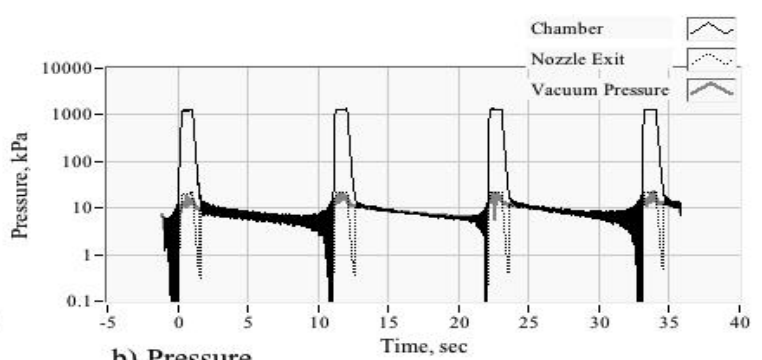

b) Pressure

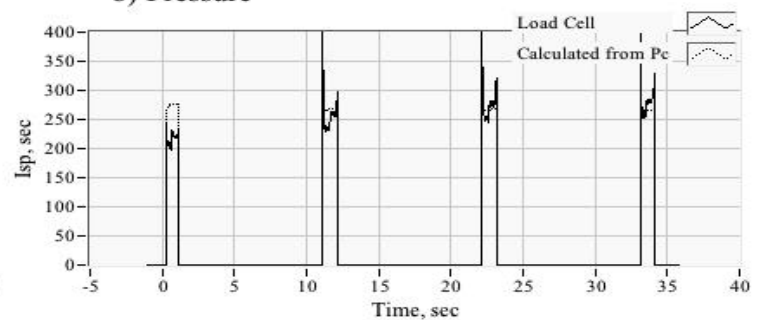

d) Specific Impulse

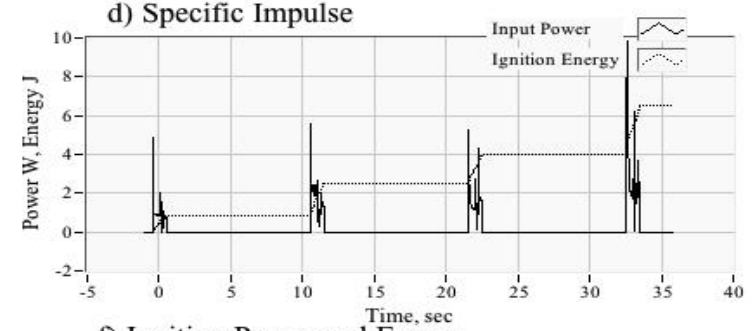

f) Ignition Power and Energy

Fig. 12 Time Histories of Pulsed Burns for Soft-Vacuum Conditions. 

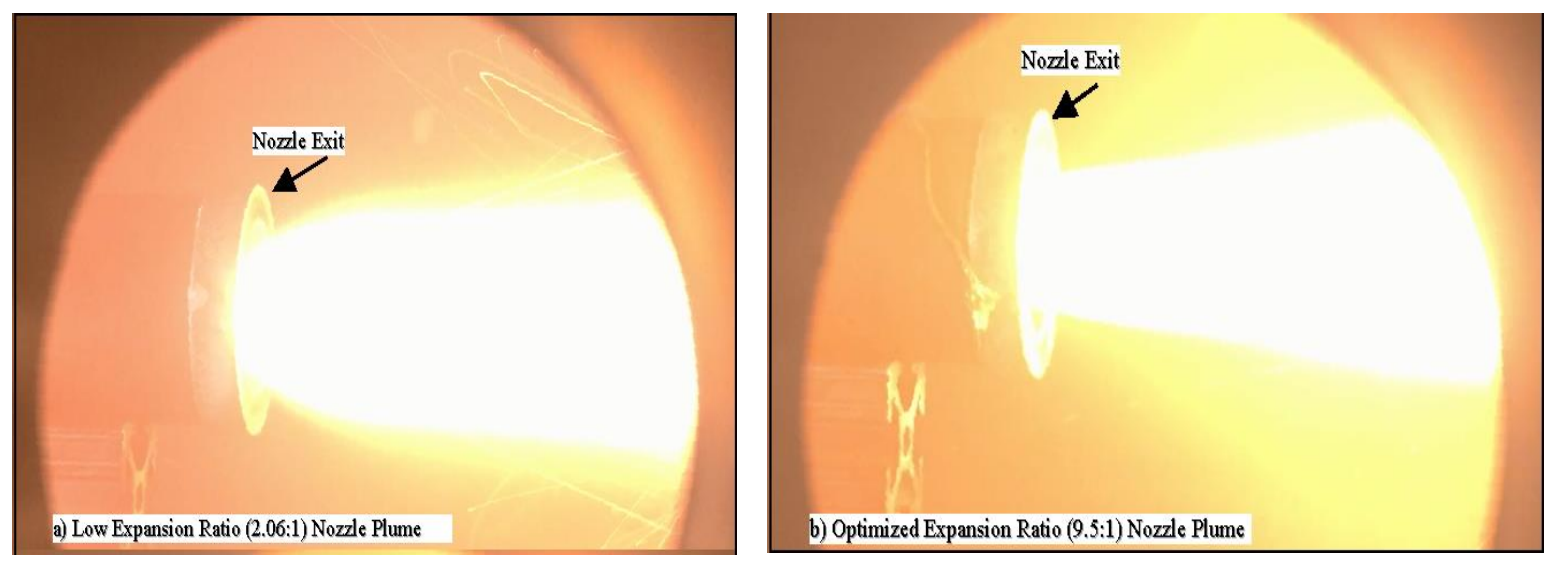

Fig. 13 Comparison of Thruster Vacuum Exhaust Plumes for 2.064:1, and 9.5:1 Expansion Ratios.

Even though the 9.5: 1 nozzle was optimized for these test conditions, the measured specific impulse of 280 seconds does not represent a true vacuum value. Using data from Table 3 , the specific impulse can be extrapolated to a hard vacuum condition by using the one-dimensional deLaval flow equations [36]. Assuming a mean chamber pressure level of $195 \mathrm{psia}(1250 \mathrm{kPa})$, test vacuum pressure of $15 \mathrm{kPa}$, a ratio of specific heats of 1.18 , the thruster with the $9.5: 1$ expansion ratio nozzle extrapolates to give a hard vacuum specific impulse of 296.5 seconds. When the nozzle is more optimized for vacuum operating conditions, e.g. $A_{\text {exit }} / A^{*}=25: 1$, then the exit pressure drops to $6.7 \mathrm{kPa}$ and the specific impulse extrapolates to 319 seconds. This value is $30-35 \%$ greater than can be achieved by mono-propellant hydrazine ${ }^{\mathrm{xxvii}}$ or either of the ionic-liquid green propellants LMP-103s ${ }^{\text {xxviii }}$ or AF-M315E..$^{\text {xix }}$

\section{Chapter IV}

\section{PLUME CONTAMINATION MEASUREMENTS}

Because the low-expansion ratio nozzle exhibited the greatest plume expansion and potential for backscatter, vacuum plume contamination measurements were obtained using the low expansion ratio nozzle. As shown by previously by Figure 5(a) the change of resistance of the $C d S$ 
photo-resistor is converted to a voltage output signal using a simple Wheatstone Bridge circuit. Under the lighting conditions experienced in the closed tunnel $\sim 5$ lumens, it was discovered that matching resistors of approximately $20 \mathrm{k} \Omega$ were able to balance the bridge output when the illuminating LED was turned off.

Using a 5-volt bridge excitation input, the corresponding bridge responses for the $R G B L E D$ outputs were approximately 1.4, 0.8, and 1.7 volts respectively. Figure 14 presents a typical plume measurement time history. Figure 14(a) plots the commanded LED logic, and Figure 14(b) plots the photometer bridge output voltage. The commanded LED modulation is a 1-Hz square wave; the bridge output signal was low passed filtered at $5 \mathrm{~Hz}$ to remove any spurious higher frequency optical inputs. The two large spikes in the middle of the voltage plot result from each of the two 1 -second rocket burns. Notice that the voltage amplitude drops slightly after the thrust is terminated. The primary cause of this short-term drop is the plume heat causing the internal chamber temperature to rise.

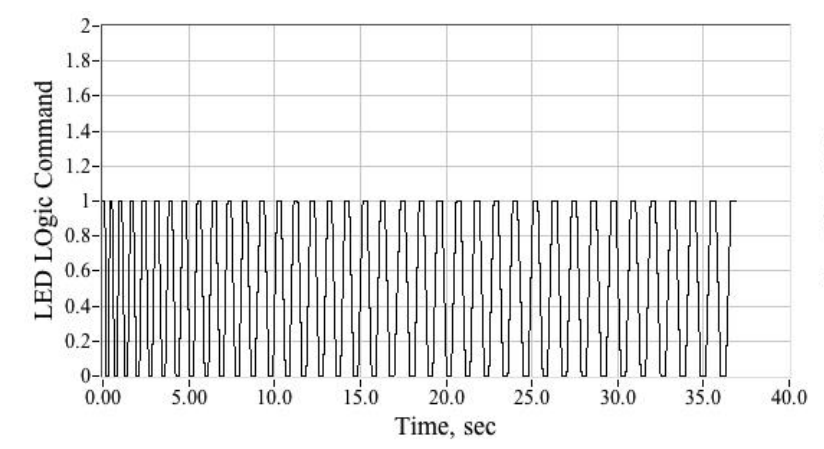

a) LED Logic Command

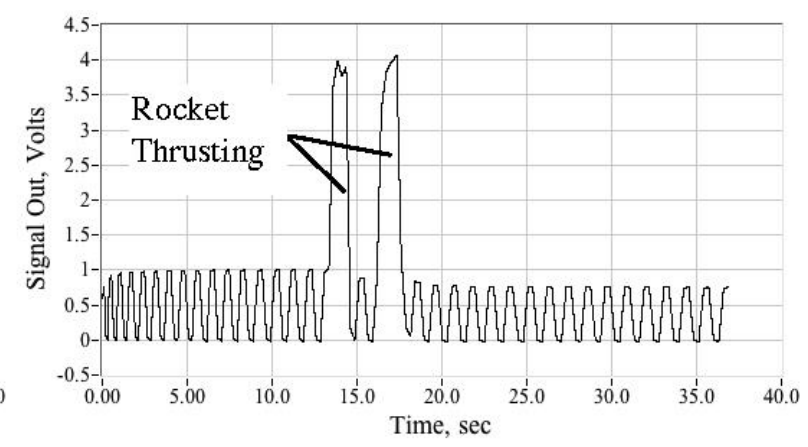

b) PhotoResistor Bridge Output Volts

Fig. 14 Typical Photometer Bridge Time History Output.

Figures 17(a) and 17(b) show the photometer response for 10 consecutive thrust burns for two sensors placed side by side as shown in Figure 11. By contrast Figure 17(a) plots the photometer response for 10 consecutive thruster burns under soft-vacuum conditions. The burn series for the Demo Test Rig (DTR) cart was done in 10 1-second pulses, with approximately 30 seconds of post 
data collection. However, this ended up being split into 3 distinct data collections due to issues while firing the thruster. Each soft of soft-vacuum burns featured two 1-second pulses, followed by 30-50 seconds of post-data collection. The bridge excitation is 5-volts, and each of the matching resistors were $20 \mathrm{k} \Omega$. The 1 -second burn intervals are clearly visible. After the post burn voltage levels stabilized the vacuum chamber was pressurized, and opened to allow the LED's optical surface to be wiped clean of any residue. The photometer surface was not cleaned after each test series, allowing a gradual build-up of surface contaminants. The LED optical surface was also wiped after every second burn during the tests on the DTR cart to more closely match the data from the vacuum chamber.

Figures 15 and 17(b) plot the peak photometer voltage output as a function of accumulated burn time. Plotted are (a) peak voltage (during burn), (b) peak stable voltage after each burn but before the LED surface was wiped clean, and (c) peak stable voltage after the LED surface was wiped clean. Clearly, there is a gradual drop off of the output voltage for all three metrics, indicating that the photo-resistor illumination level is also dropping.

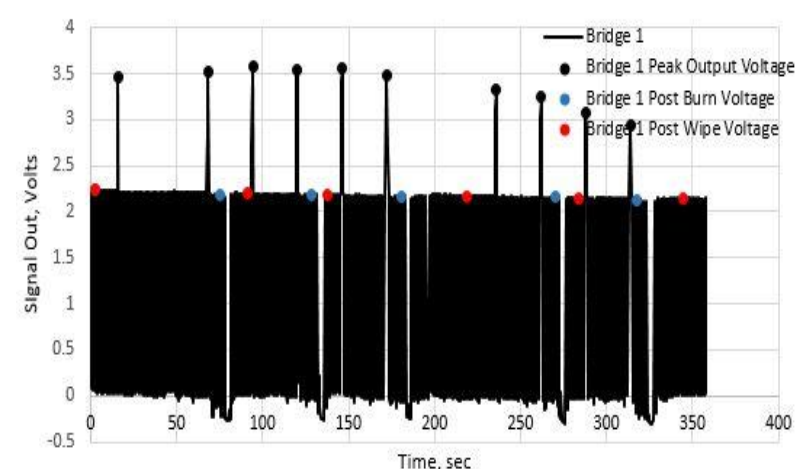

a) Photoresistor Bridge Output Volts (Bridge 1)

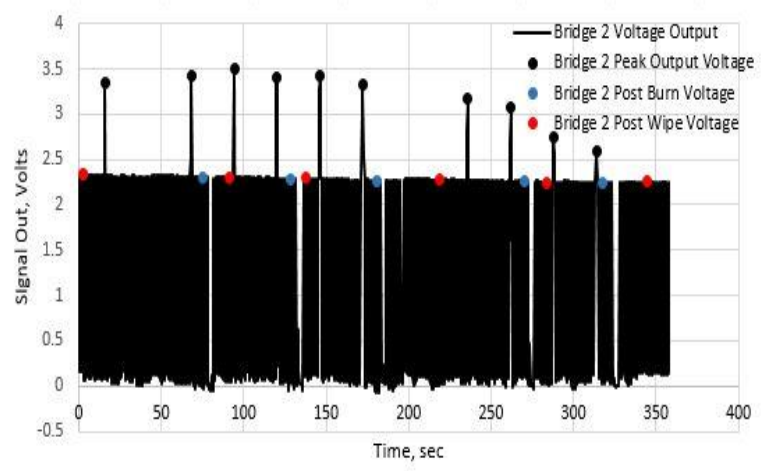

b) Photoresistor Bridge Output Volts (Bridge 2)

Fig. 15 Photo Resistor Bridge Time History Output from 10 Consecutive Thruster Burns. 

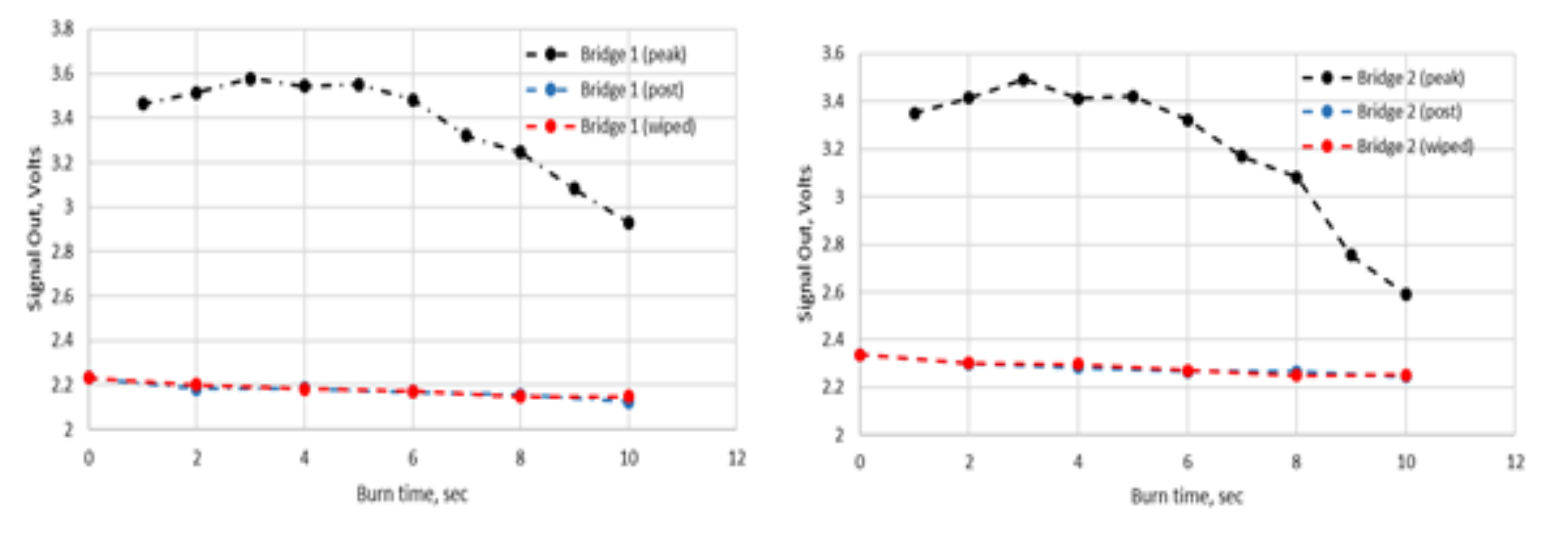

Fig. 16 Photoresistor Bridge Peak Output Volts as a function of Burn Time (DTR).

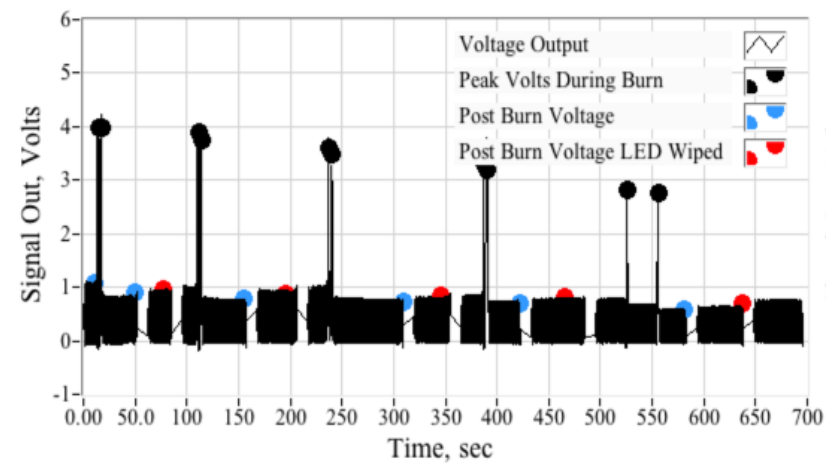

a) PhotoResistor Bridge Output Volts

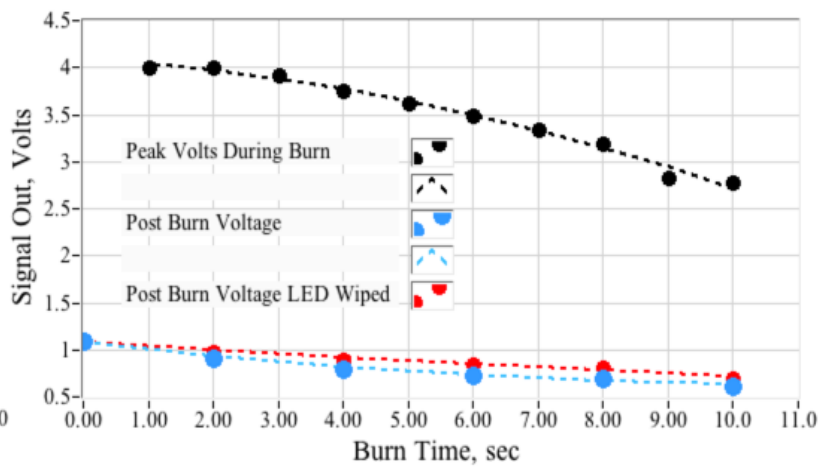

b) PhotoResistor Bridge Peak Output Volts as Function of Burn Time

Fig. 17 Photoresistor Bridge Time History Output from 10 Consecutive Thruster Burns (Vacuum).

\subsection{EFFECT OF PLUME CONTAMINATION ON PHOTOMETER ILLUMINATION LEVEL}

The drop off in illumination is calculated using the post burn peak amplitudes; both before and after the LED surface was wiped clean. The calculation starts with the Wheatstone Bridge resistance equation

$$
\frac{V_{\text {out }}}{V_{\text {ex }}}=\frac{R_{1} \bullet R_{x}-R_{2} \bullet R_{3}}{\left(R_{1}+R_{2}\right) \bullet\left(R_{3}+R_{x}\right)},
$$

and solving for the photo-resistor value 


$$
R_{x}=R_{3}\left(\frac{R_{2}+\left(\frac{V_{\text {out }}}{V_{\text {ex }}}\right) \bullet\left(R_{1}+R_{2}\right)}{\left(\frac{V_{\text {out }}}{V_{\text {ex }}}\right) \bullet\left(R_{1}+R_{2}\right)}\right) \bullet \frac{\left(\frac{V_{\text {out }}}{V_{\text {ex }}}\right) \bullet\left(R_{1}+R_{2}\right)}{R_{1}-\left(\frac{V_{\text {out }}}{V_{\text {ex }}}\right) \bullet\left(R_{1}+R_{2}\right)}
$$

Assuming that the three fixed bridge resistors have identical values $R$, then Eq. (2) reduces to

$$
R_{x}=R \bullet\left(\frac{1+2 \bullet\left(\frac{V_{\text {out }}}{V_{e x}}\right)}{1-2 \bullet\left(\frac{V_{\text {out }}}{V_{\text {ex }}}\right)}\right) .
$$

Calculating the normalized sensitivity of a change in resistance to the normalized change in output voltage, then

$$
\frac{\partial R_{x}}{R_{x}}=\frac{4 \bullet\left(\frac{\partial V_{\text {out }}}{V_{\text {ex }}}\right)}{\left(1-4 \bullet\left(\frac{V_{\text {out }}}{V_{\text {ex }}}\right)^{2}\right)}
$$

From the data presented by Figure 6(a) the photo-sensor resistance can be curve fit as a function of the illumination level as

$$
R_{x}=(\operatorname{lux})^{a} \bullet 10^{b} \rightarrow\left[\begin{array}{c}
a=-0.7025 \\
b=1.7954
\end{array}\right]
$$

Solving for the normalized sensitivity of a change in illumination to the normalized change in output voltage

$$
\frac{\partial l u x}{l u x}=\frac{1}{a} \frac{\partial R_{x}}{R_{x}}=\frac{1}{a} \bullet \frac{4 \bullet\left(\frac{\partial V_{o u t}}{V_{e x}}\right)}{\left(1-4 \bullet\left(\frac{V_{o u t}}{V_{e x}}\right)^{2}\right)} \approx \frac{5.694 \cdot\left(\frac{\partial V_{o u t}}{V_{e x}}\right)}{\left(1-4 \bullet\left(\frac{V_{o u t}}{V_{e x}}\right)^{2}\right)}
$$


Equation (6) is used to calculate the estimated optical attenuation that corresponds to the post-burn data plotted on Figure 17 (b). Figures 18-20 plot these results. Figures 18 and 20(a) plot the fraction of original illumination, and Figures 19 and 20(b) plot the attenuation fraction. The total motor burn time is plotted on the abscissa for both graphs. The measured illumination attenuation of between 9 and $13 \%$ occurs in spite of the fact that there was no visible contamination apparent of the photometer's optical window.

The devised method is quite sensitive to optical contamination, and will prove to be a very robust and inexpensive tool for further contamination studies. Preliminary results indicate that plume contaminations result in an optical surface luminous flux deterioration slightly greater than $1 \%$ of the "clean surface" illumination for each second of burn time. Also, at this point it is unclear as to what fraction of the observed contamination levels are generally applicable to a hard-vacuum, free space condition, and what fraction is an artifact of the test apparatus arrangement and the relatively small vacuum chamber. At the current level of understanding, the authors conclude that this level of contamination, although measurable, is generally not alarming. Clearly, a more comprehensive study must be performed in order to assess the total field contamination levels.

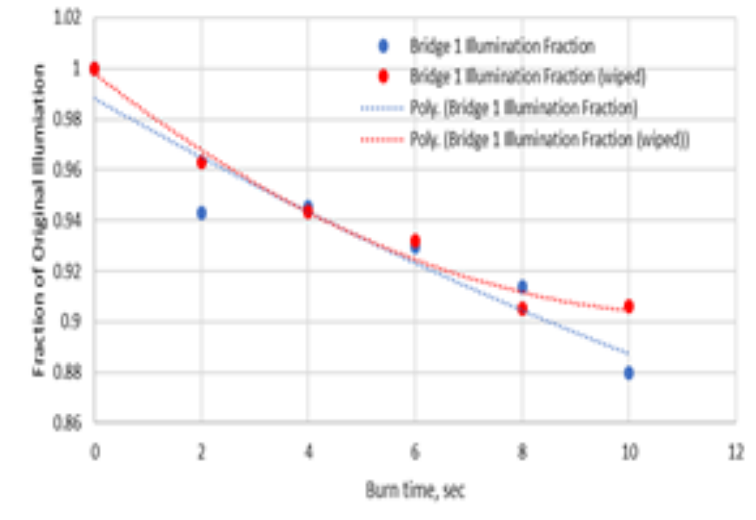

a) Fraction of Original Illumination (Bridge 1)

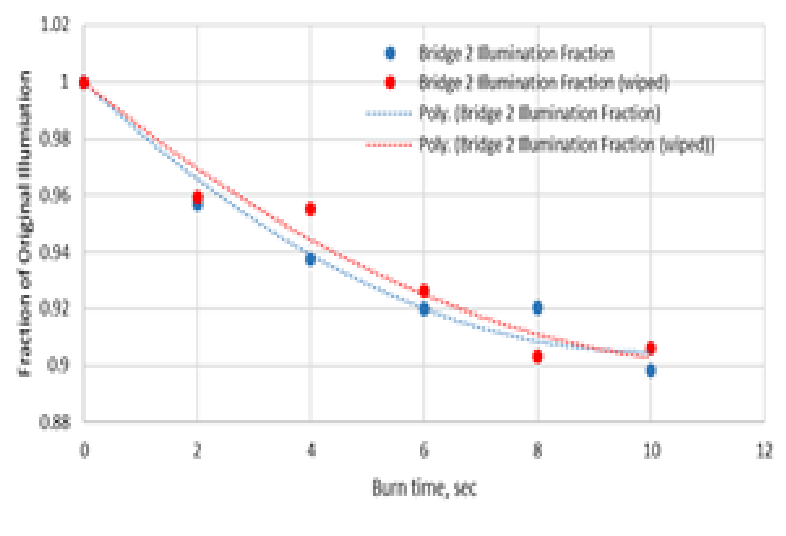

b) Fraction of Original Illumination (Bridge 2)

Fig. 18 Photoresistor Bridge Time History Fraction Output from 10 Consecutive Thruster Burns. 


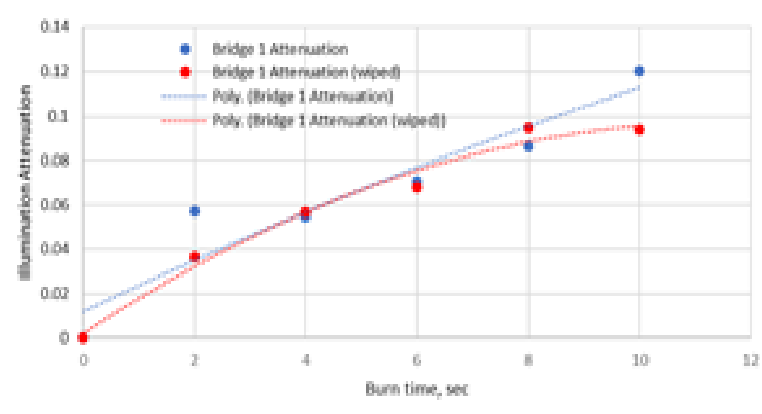

a) Illumination Attenuation (Bridge 1)

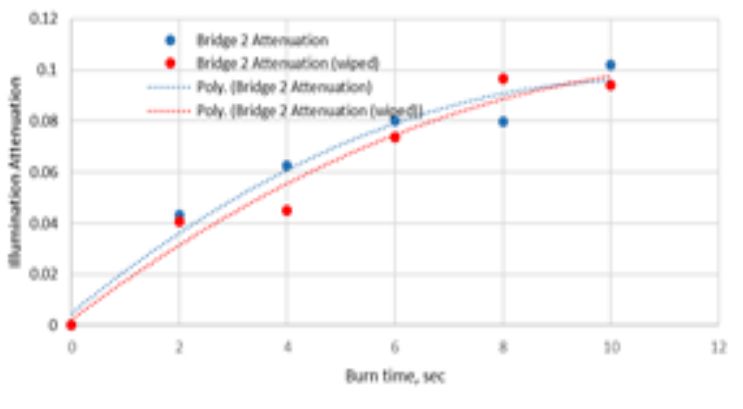

b) Illumination Attenuation (Bridge 2)

Fig. 19 Photoresistor Bridge Time History Attenuation Output from 10 Consecutive Thruster Burns.

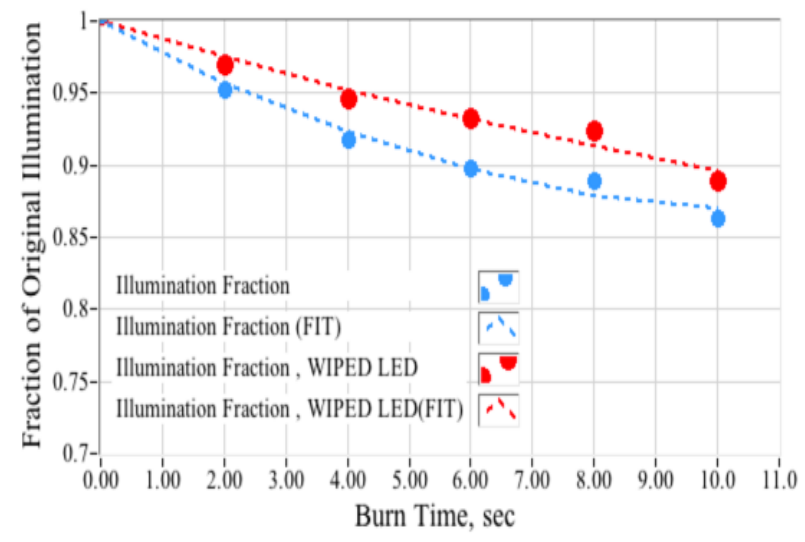

a) Fraction of Original Illumination

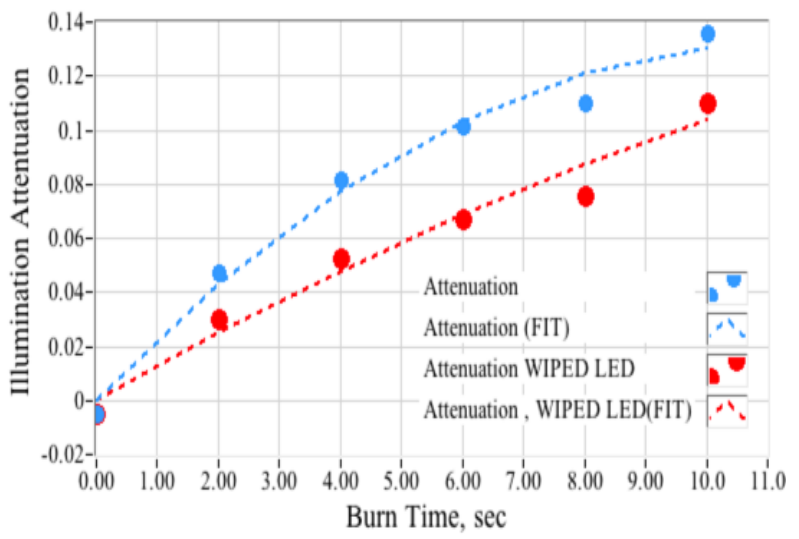

b) Illumination Attenuation

Fig. 20 Photo Resistor Bridge Time History Fraction Output from 10 Consecutive Thruster Burns (Vacuum).

\subsection{SCANNING ELECTRON MICROSCOPE ANALYSIS OF BRIDGE PHOTOMETERS}

As seen in Figure 6 each of the Photometers used included a thin transparent shield for the photoresistor from the contamination of the thruster plume. While the shield used in the vacuum chamber testing was an acrylic plastic and as such made primarily from carbon, the shield for the DTR cart was from a silicon based glass. The Scanning Electron Microscope (SEM) at the USU Microscopy Core facility was employed to determine the chemical composition of the contamination on the glass shields used for the DTR cart. The photometers were approximately 12 inches from the space shuttle tile that simulated vacuum conditions backscatter. Additionally, a piece of glass of approximately the same size and thickness that was not exposed to the 
contamination from the thrust plume was placed in the SEM to provide a basis of comparison.

Figures 21 and 22 below are included to show the specific SEM used to conduct the analysis.

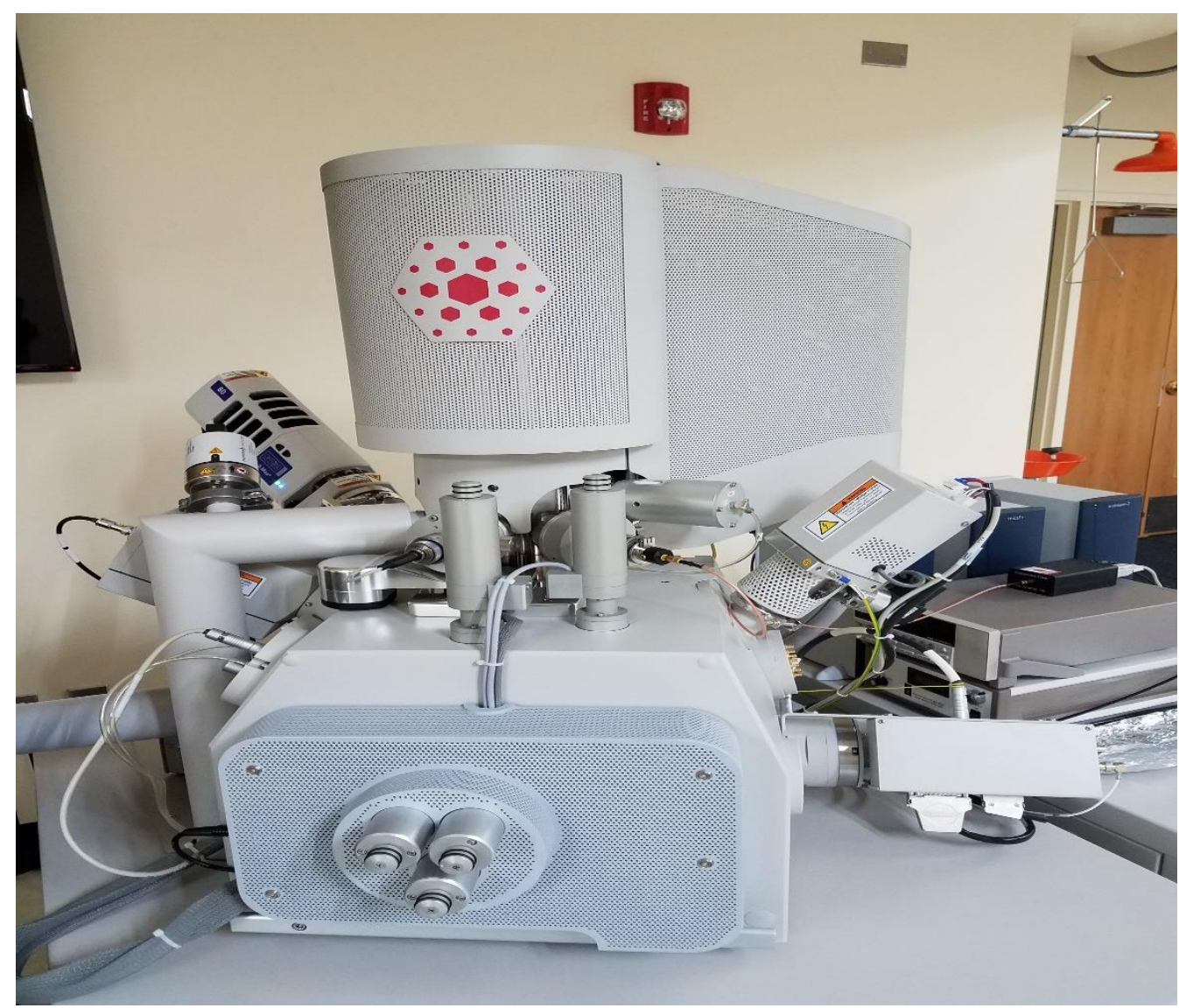

Fig. 21 External Picture of the SEM employed at USU.

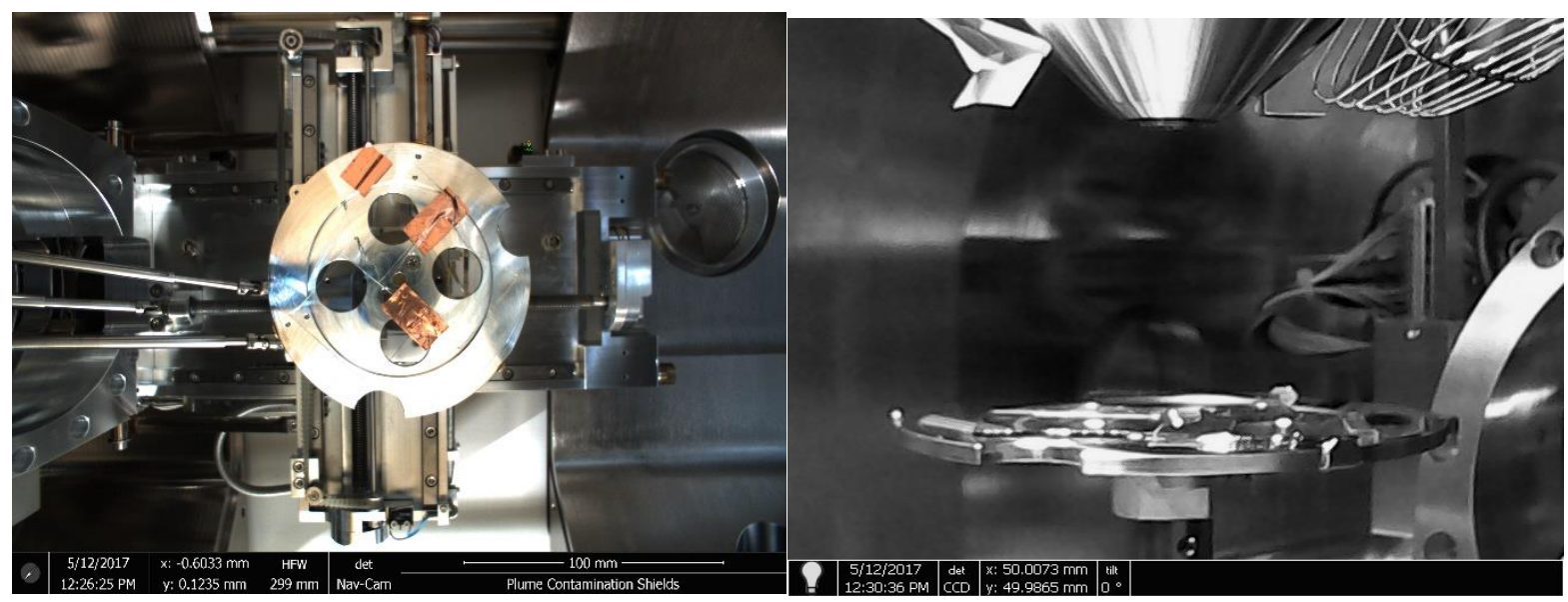

Fig. 22 Internal Pictures of the SEM employed at USU (Left: Top view, Right: Front view). 
This SEM was employed in Low vacuum mode at approximately 0.3 torr because the glass shields are non-conductive. While visual comparison of the glass after contamination reveals no obvious imperfection viewing it in the SEM at 500x magnification does show obvious (if small) pockets of carbon from the thruster plume. However, by comparing Figure 23 with Figures 24 and 25 it can be seen that the overall amount of carbon increase on the shields after the thruster burns is very small.
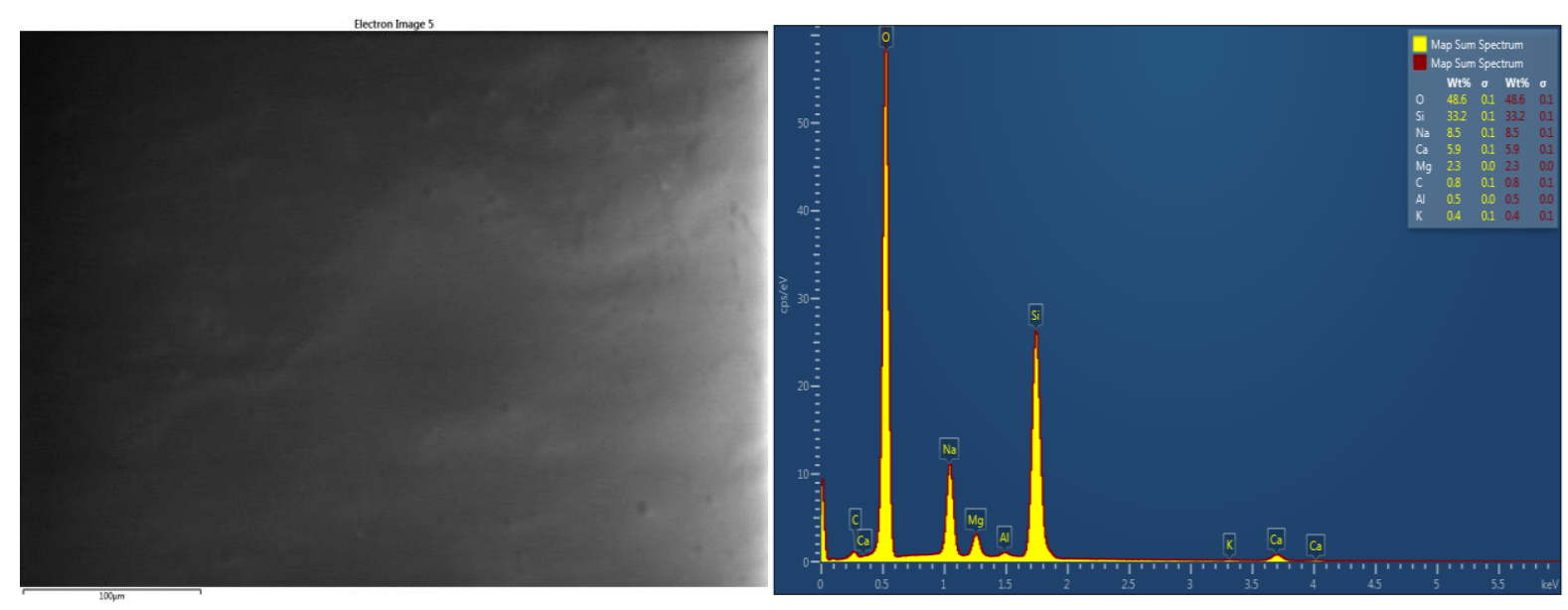

Fig. 23 SEM results for the clean glass piece (Left: Picture at 500x, Right: Chemical composition).

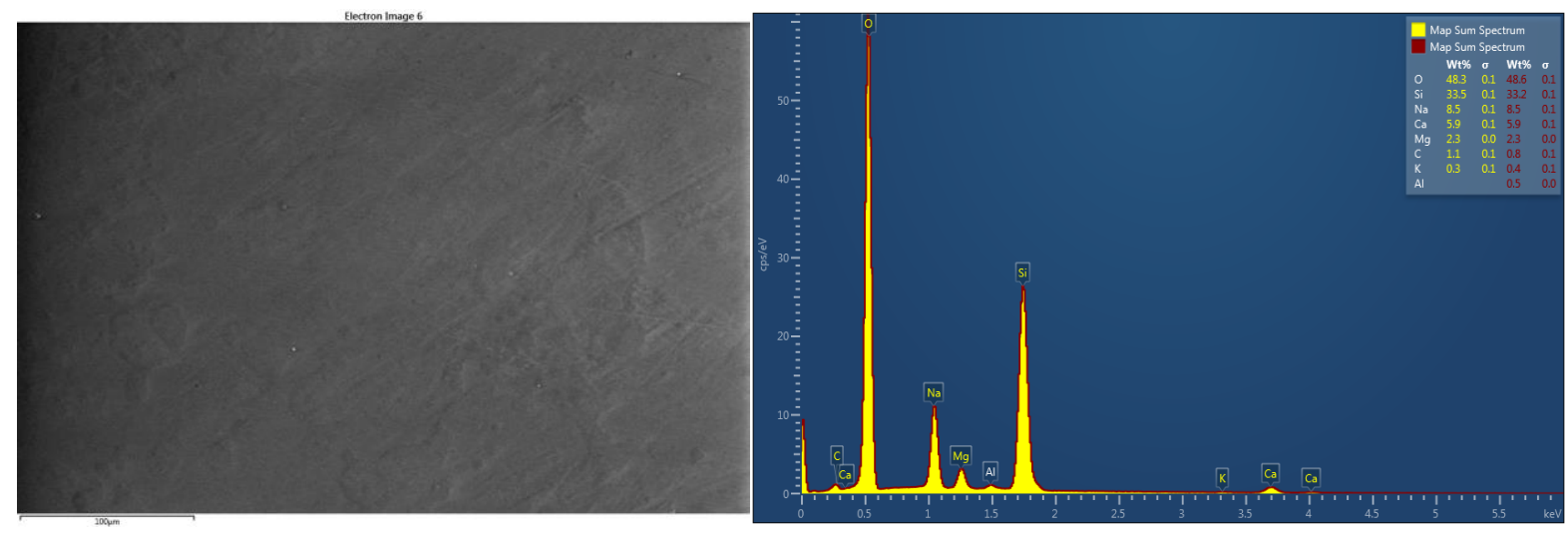

Fig. 24 SEM results for the bridge 1 shield (Left: Picture at 500x, Right: Chemical composition). 


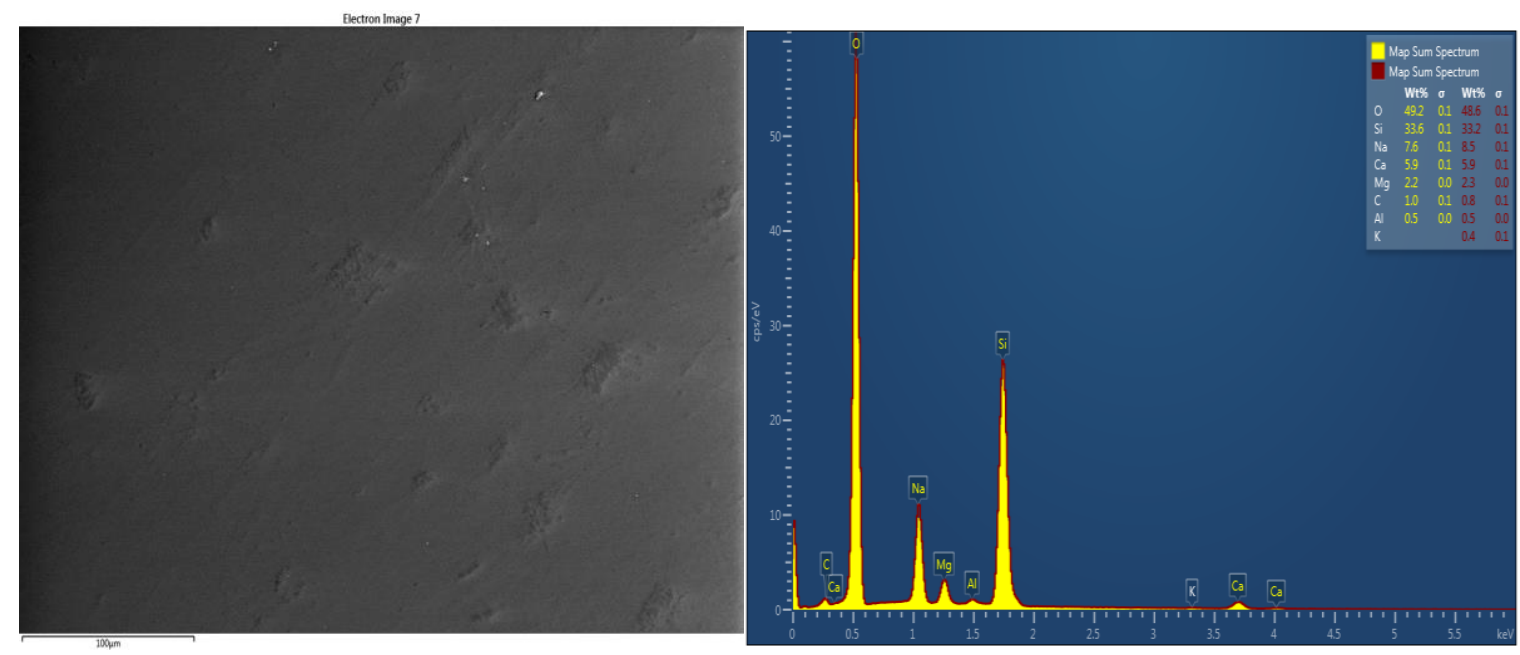

Fig. 25 SEM results for the bridge 2 shield (Left: Picture at 500x, Right: Chemical composition).

\section{CHAPTER V}

\section{FLIGHT TEST}

In March of 2018, a system based on the ABS/GOX hybrid was tested on a Terrier Improved Malemute rocket via the NASA Undergraduate Student Instrument Project (USIP). The rocket is shown at the time of launch in Figure 26. One of the most notable differences between the two systems is that the rocket that flew during USIP used enriched air rather than GOX. This is because, GOX at low pressures is rather low density compared to hydrazine, and in order to ensure a high level of volumetric efficiency, GOX must be stored at very high pressures, greater than 3000 psig. GOX stored at high pressures creates a high level of fire danger, and precision cleaning and maintenance of spacecraft components is required. The use of GOX-rated aerospace components are also required for safe operation. These specialized requirements can lead to cost-prohibitive system designs. However, most materials designed for use with standard air delivery can be adapted for use with enriched air -- up to $40 \%$ oxygen concentration -- with little or no hardware modifications. Precision cleaning, logging, and tracking of flow path components is not required. Thus, if the green thruster system designed for GOX usage can be 
demonstrated to perform effectively using enriched air, these exists the potential for a significant reduction in operating costs.

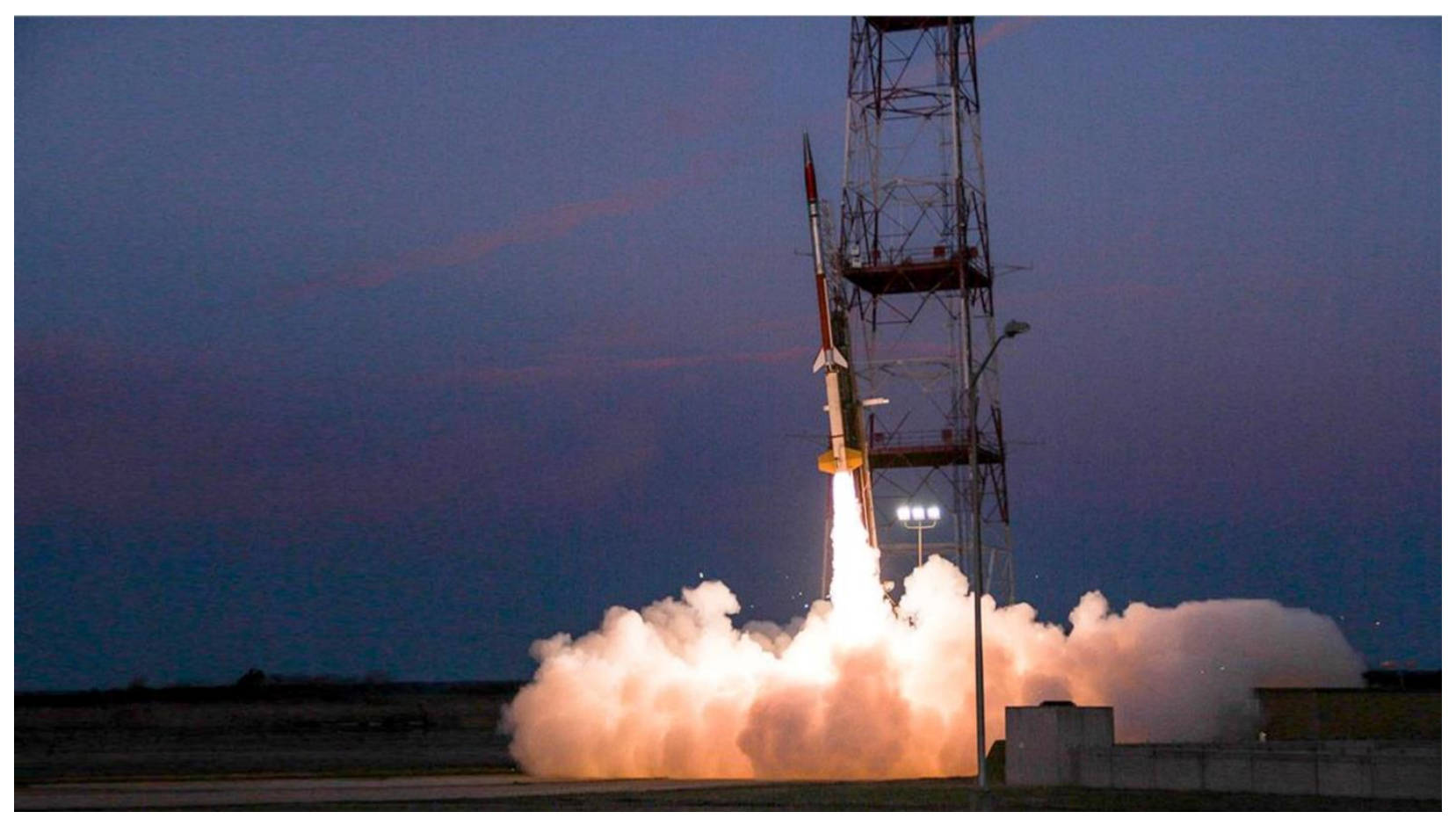

Fig. 26 Terrier Improved Malemute rocket launched for NASA USIP 2018.

The other major differences were that the system had to be constructed flight ready, small enough to be inserted into the payload section of the rocket, and that a self-nulling design was employed rather than a single thruster. The USIP rocket was launched above the Von Karman line to allow the various student projects to be tested and operated in hard vacuum conditions. This was illustrated in the Concept of Operations (CONOPS) for the project, shown as Figure 27 below. The major difficulty of the project stemmed from the need to make a system that was flight ready and small enough to fit the standard RockSat deck 12 inches in diameter and 10.75 inches tall. Figures 28 is an illustration that was generated during the USIP project to see a CAD model of the proposed test assembly contrasted with the relative size of the rocket. Figures 29 and 30 show the USU rocket assembly used at Wallops Flight Facility and give an idea of its actual size. 
Flight Tests Concept of Operations

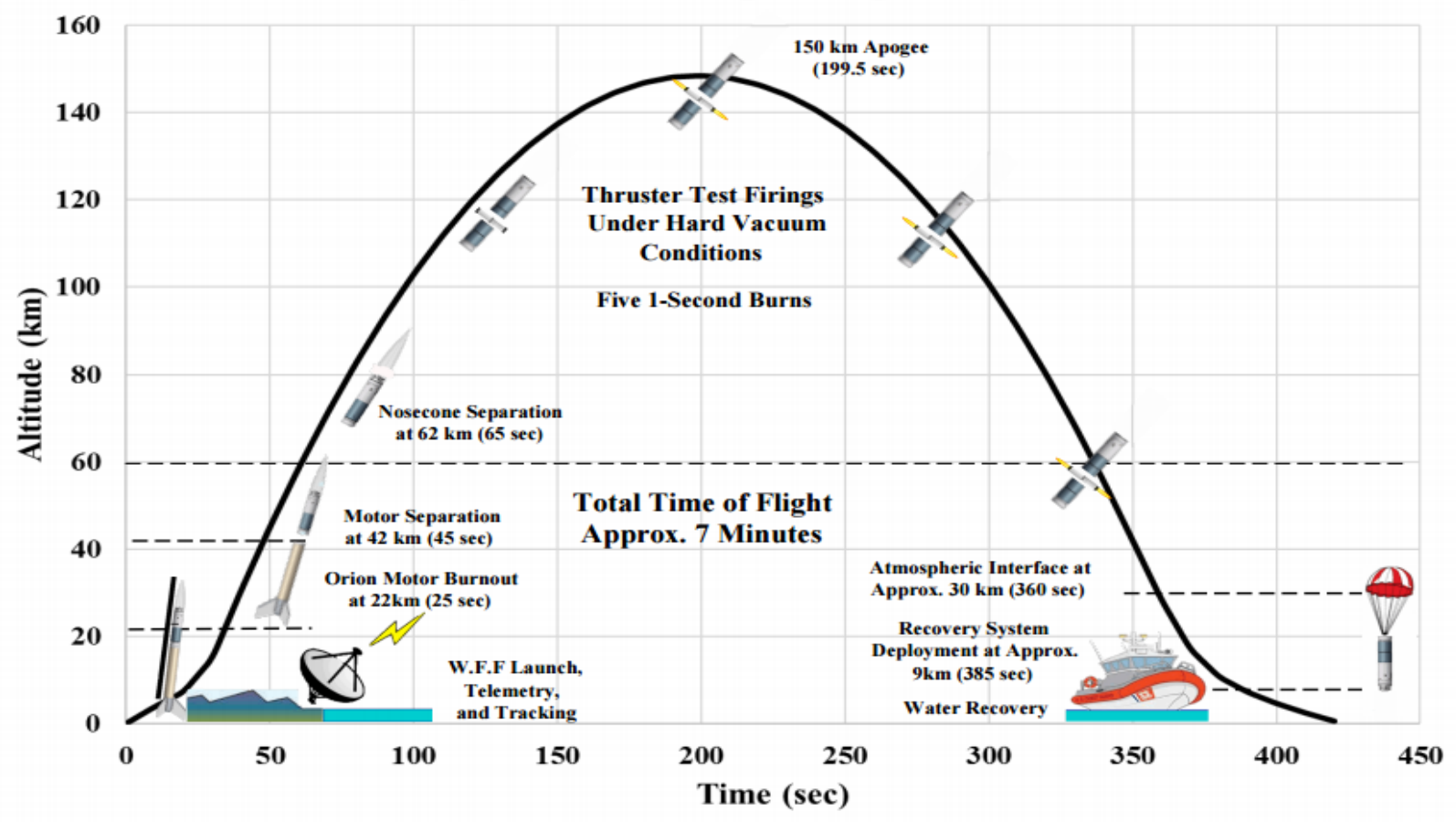

Fig. 27 USIP 2018 CONOPS for USU.

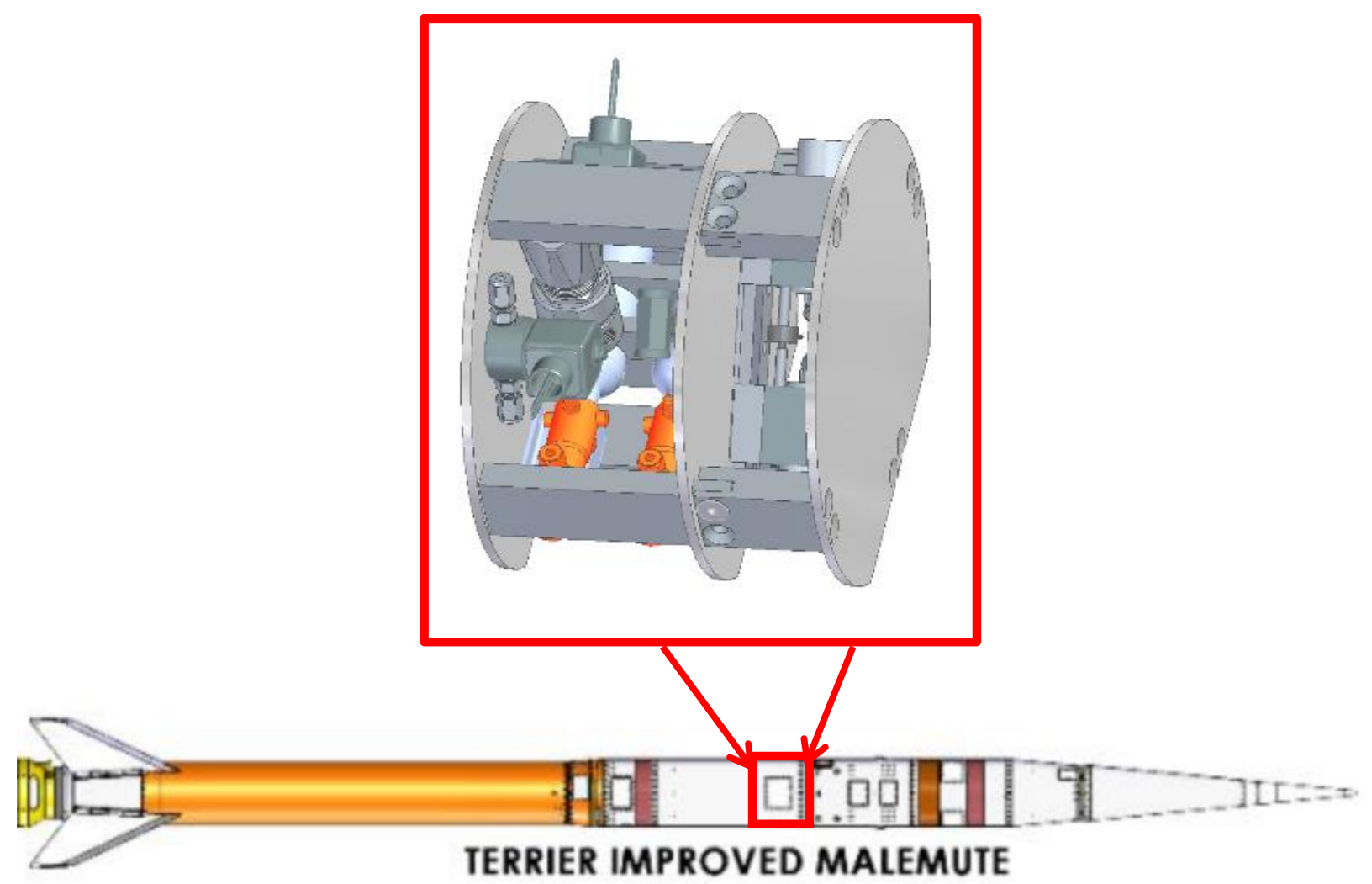

Fig. 28 RockSat Deck and location of payload on the rocket. 


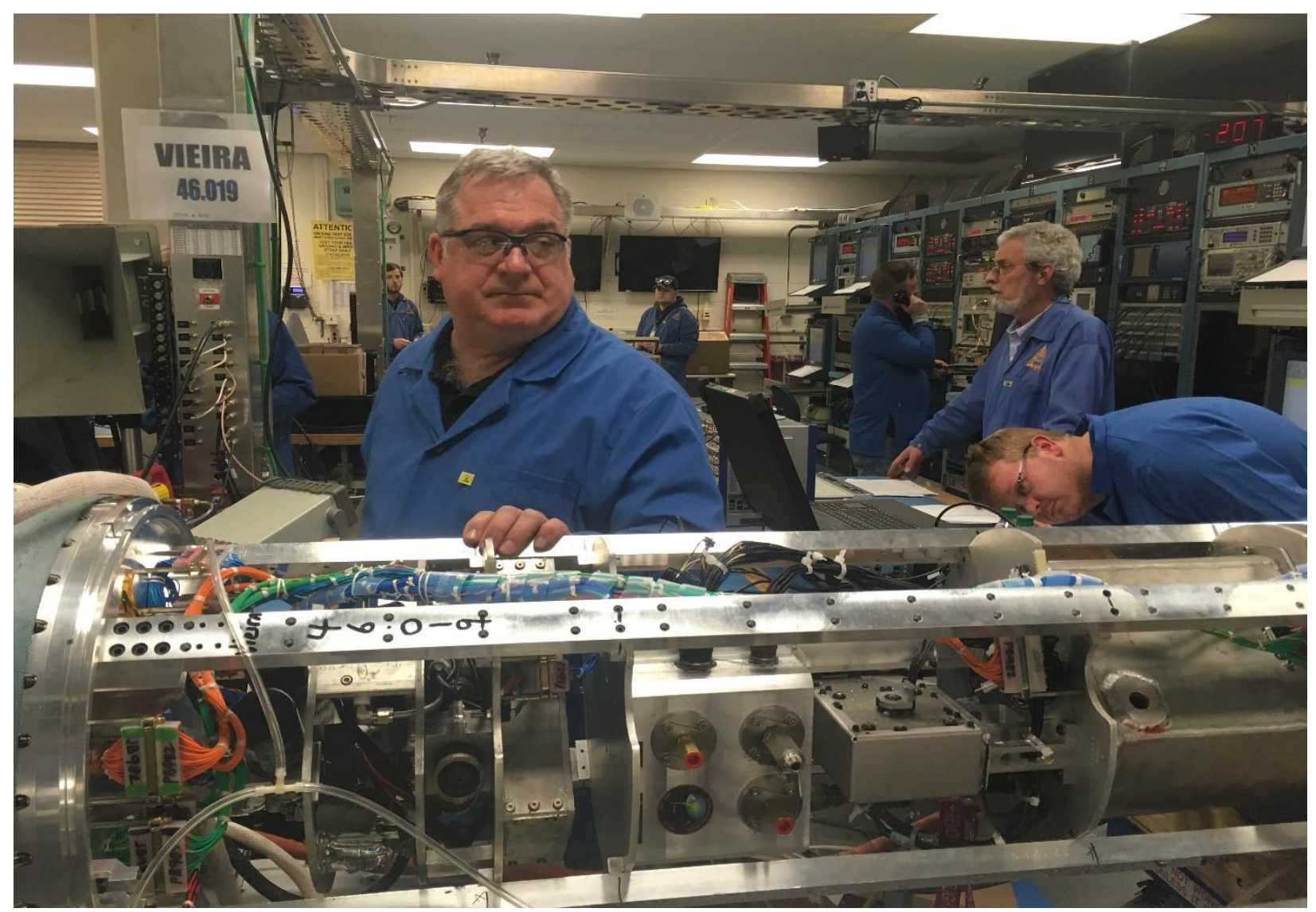

Fig. 29 USIP payload integration onto Terrier Improved Malemute.

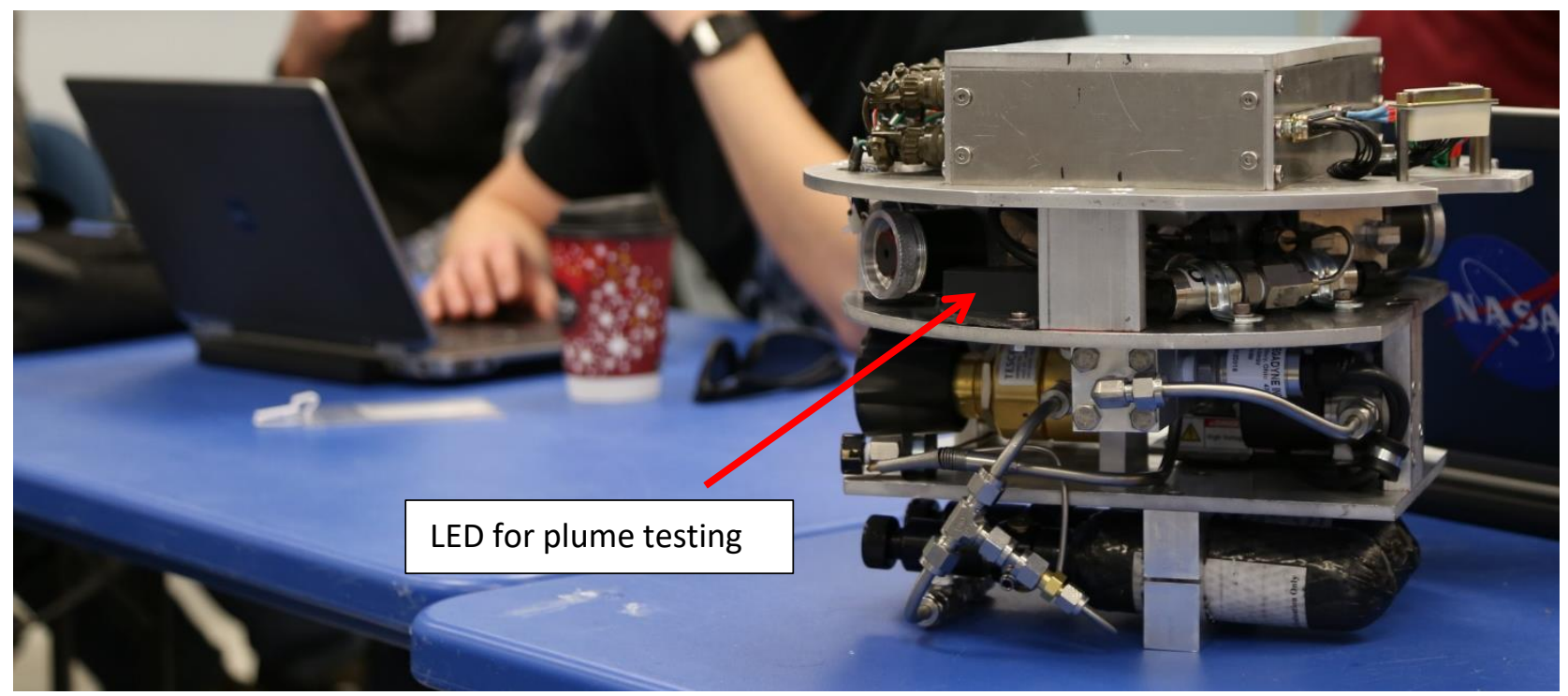

Fig. 30 USU Assembly awaiting installation. (Photoresistor and Wheatstone bridge hidden behind the thruster) 


\subsection{USIP PLUME CONTAMINATION TEST RESULTS}

The most significant success for the plume contamination testing from the USIP launch was that despite the hard vacuum conditions and other difficulties that occurred prior to the launch, the photometer still showed an observable degradation as seen in Figure 31.

\section{Illumination \%}

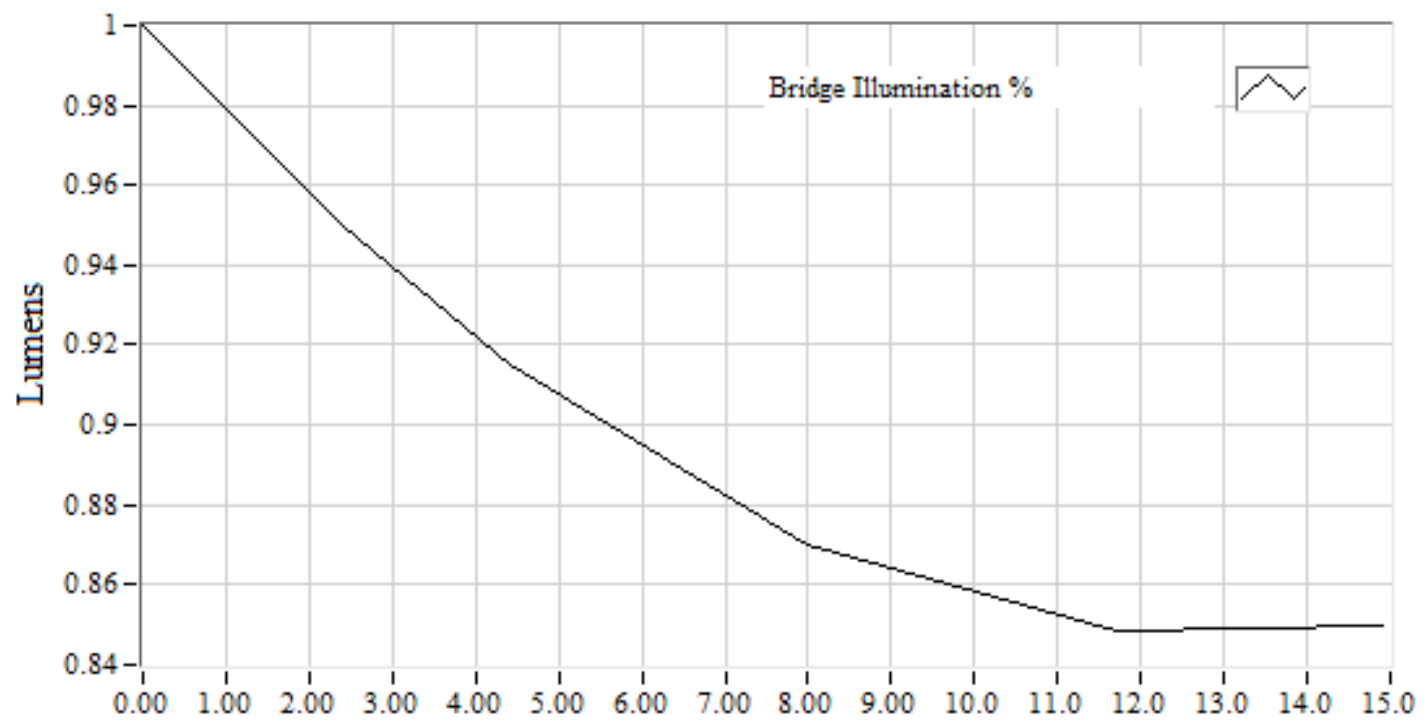

Burn Time, sec

Fig. 31 Fraction of Original Illumination. (USIP Flight Data)

Additionally, it can be noted that even though only one photometer was installed the contamination that was observed can be clearly seen to be the result of both thrusters. Figures 32 and 33 show both the voltage response of the photometer and the chamber pressure of both thrusters. Comparing the two figures at approximately 16 seconds where true ignition of the far thruster occurred and the following reduction of output voltage for the photometer strongly supports the idea that the contamination from both thrusters is observed. The noticeably lack of an illumination spike on the photometer shows that the thruster nearest to the photometer never had true ignition. The chamber pressures for both thrusters suggest that both thrusters had issues igniting until the fourth burn where the other thruster finally ignited and burned properly for both of the remaining burns. The difficulties in achieving ignition are believed to be a combination of 
the low temperatures and high moisture content around the assembly for the time preceding the launch. Despite that complication, the thrusters did receive the necessary spark to ignite but rather than burning the fuel properly only smoldered.

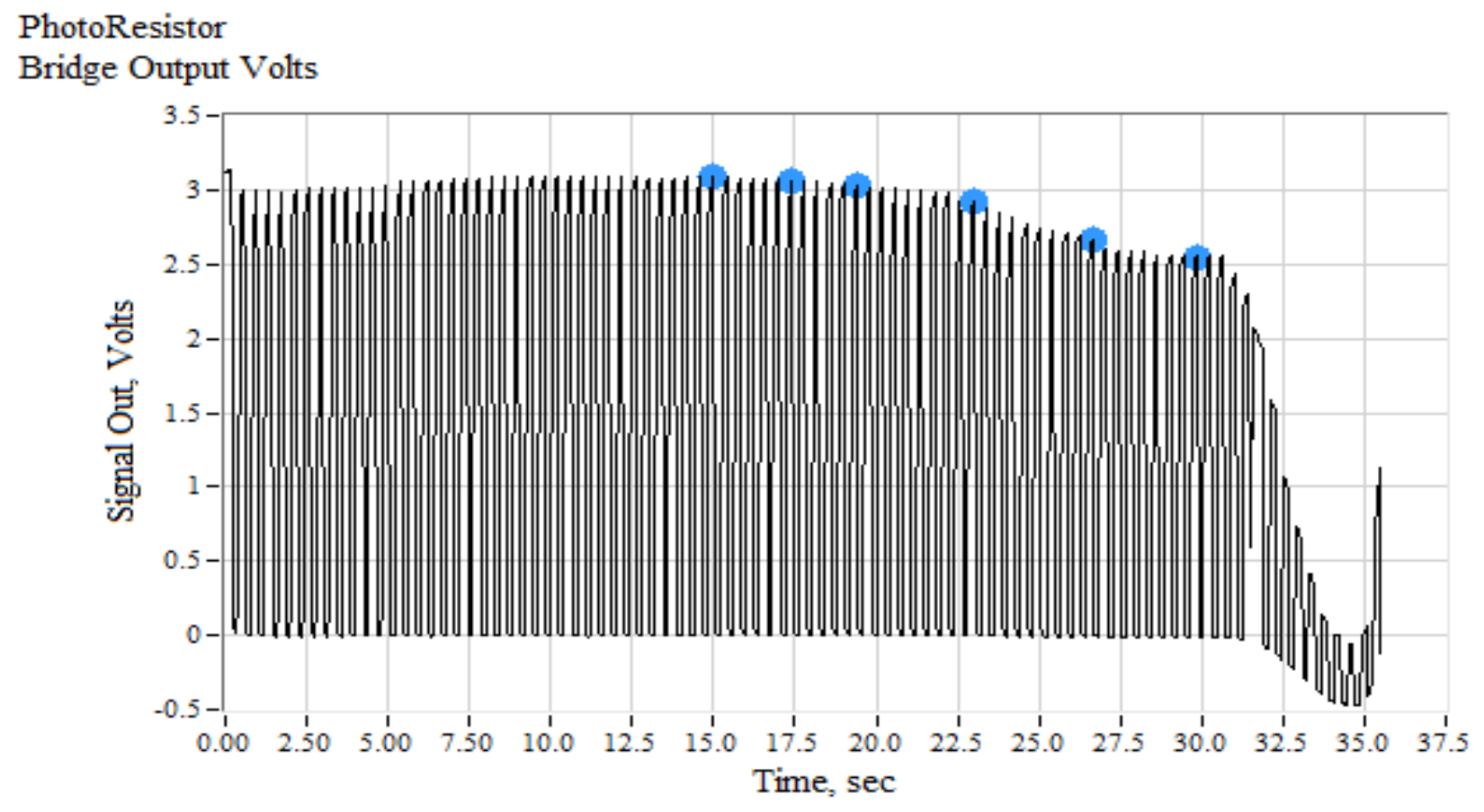

Fig. 32 Bridge Output Voltage. (USIP Flight Data)

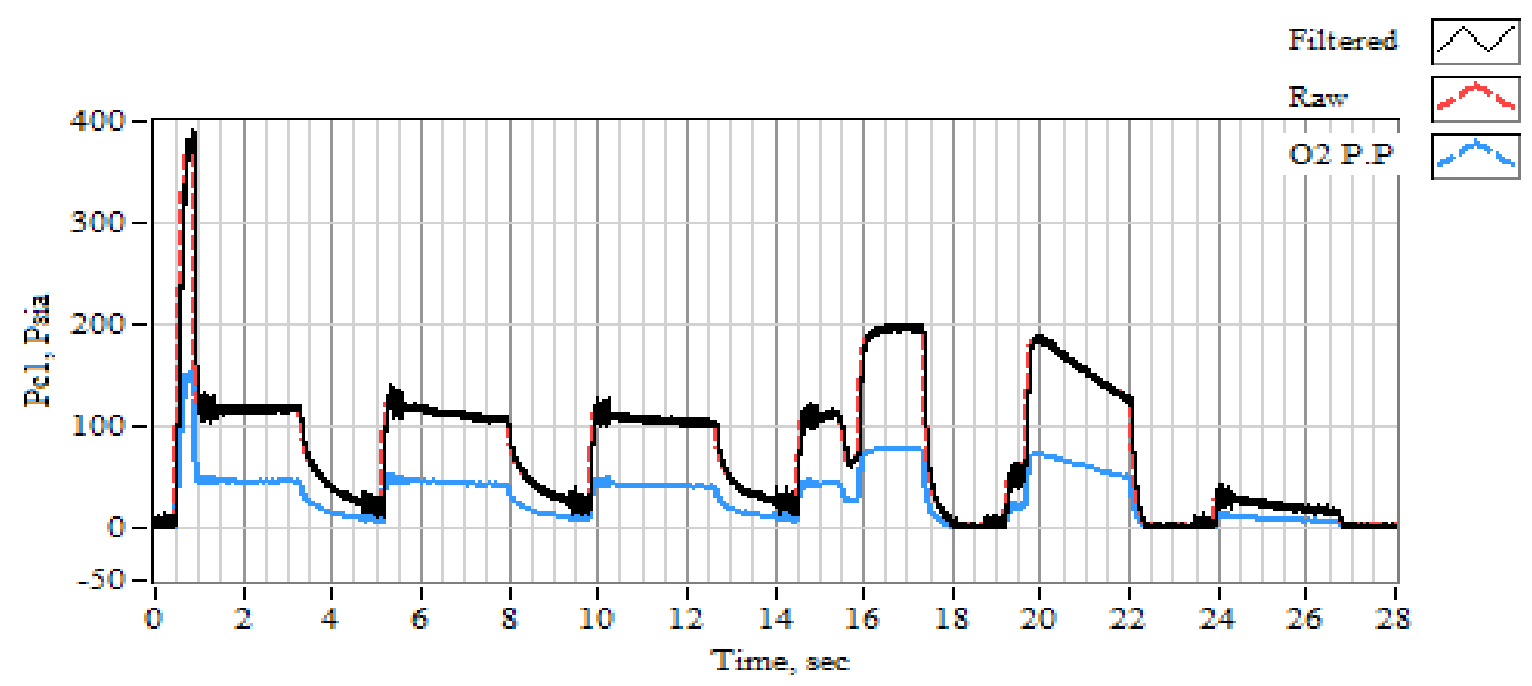

(a) Chamber Pressure 1

Fig. 33 Chamber Pressure for both thrusters in USIP. (Blue: Near, Black: Far) 
Finally, the mass flow from the USIP flight, shown in Figure 34, indicates that significant amounts of fuel was burned from both thrusters which supports the theory that smoldering occurred in both thrusters during the times where true ignition did not occur.

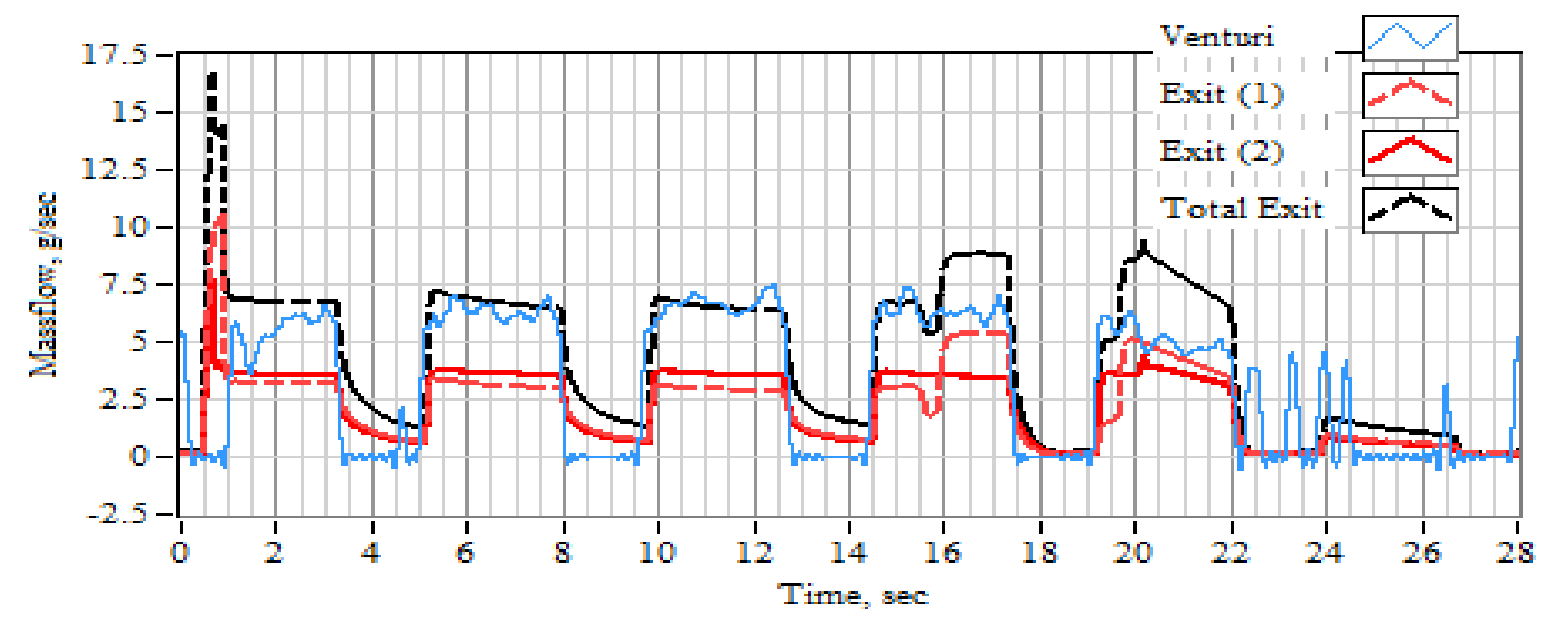

(d) Massflow

Fig. 34 Mass flow for both thrusters in USIP. 


\section{CHAPTER VI \\ SUMMARY AND CONCLUSIONS}

Historically, hybrid rocket systems have never been seriously considered for in-space propulsion due to the lack of a reliable, low energy, multiple-use, and on-demand ignition system. Recently however, the Propulsion Research Laboratory at Utah State University has developed a patented USU arc-ignition system that overcomes multiple technical difficulties allows hybrid motors to be started, stopped, and restarted with low power input and a high degree of reliability. The technology is derived from the unique electrical breakdown properties of 3-D printed acrylonitrile butadiene styrene (ABS), discovered serendipitously while investigating the thermodynamic performance of $\mathrm{ABS}$ as a hybrid rocket fuel. Additive manufacturing is an essential feature of this configuration. Because additive manufacturing builds the specimen one layer at a time, 3D-printed ABS possesses unique electrical breakdown properties that have been exploited to allow for rapid on-demand system ignition.

Because ABS is an entirely new material for propulsion applications, and no database exists to describe the potential deleterious effects of the exhaust plume on spacecraft surfaces. In fact, the authors could find no published literature presenting plume contamination measurements for any type of hybrid rocket. The adsorption of propellant effluents on spacecraft surfaces can create multiple operational concerns; for example, the collection of molecules on solar arrays and thermal control surfaces can lead to decreased power production and increased spacecraft temperatures.

The presented results begin the process of quantifying the expected contamination levels generally for hybrid rockets in general, and specifically for 3-D printed ABS-based fuels. Presented equilibrium chemistry calculations have allowed the authors to conclude that when the GOX/ABS motor is operated near the optimal $\mathrm{O} / \mathrm{F}$ ratio between 1.5 and 2.0, the combustion 
products are relatively benign, and this burn profile generally results in "clean" exhaust byproducts with $\mathrm{C}(\mathrm{gr})$, and carbon monoxide levels half of what is produced when traditional petroleum based hydrocarbons are burned.

Most importantly, presented data demonstrate that GOX/ABS combustion does not produce ammonia decomposition products. The vast majority of operational spacecraft have relied on hydrazine as the main propellant. Highly fluent and condensable ammonia is an abundant byproduct of hydrazine decomposition, and over the lifetime of a spacecraft can result in significant contamination of critical spacecraft surfaces. The GOX-ABS hybrid does not produce highlyfluent by products. This, the potential for contamination is significantly reduced when compared to traditional in-space thruster systems

Acidic products like Hydrogen cyanide gas are produced only when the motor is run extremely fuel rich, at equivalence ratios above approximately 2.3. The results demonstrated from the Scanning Electron Microscope (SEM) confirm that the only particulate contaminate that results from the thruster plume is carbon which can be mitigated by running the motor fuel lean.

The presented plume measurements demonstrate that the photometer design is quite sensitive to optical contamination, and will prove to be a very robust and inexpensive tool for further contamination studies. Following a 10-burn cycle, this instrument measured an optical illumination attenuation of between 9 and $13 \%$ occurs in spite of the fact that there was no visible contamination apparent of the photometer's optical window. At the current level of understanding, the authors conclude that this level of contamination, although measurable, is generally not alarming.

The results from the USIP flight test data clearly indicate that this contamination system can be successfully employed to detect contamination of a GOX/ABS thruster even under hard vacuum conditions. The approximate optical illumination attenuation of $15 \%$ supports the 
conclusion that the level of contamination is not problematic. Additionally, the fact that this flight used $40 \%$ enriched air in lieu of GOX, the ignition difficulties, and the fact that the photometer was clearly detecting contamination from both thrusters suggest that the actual attenuation level might have been lower under more optimal conditions. 


\section{CHAPTER VII}

\section{FUTURE WORK}

At this point it is unclear what fraction of the observed contaminations are generally applicable to a hard-vacuum, free space conditions; as compared to the extraneous contamination resulting from the test apparatus and the relatively small vacuum chamber. Clearly, a more comprehensive study must be performed in order to assess the total field contamination levels. Although the test data suggests that most of the contamination observed was from the artificial backscatter of the Vacuum chamber, the amount of noise in the data requires that additional testing be conducted to confirm this. Recently, USU completed testing of a NASA funded flight using the prototype "green" ABS/GOX thrusters launched to an apogee of 150 kilometers altitude aboard a Terrier Improved Malemute sounding rocket. The rocket launched from the Wallops Flight Facility's East Coast Rest range. The test platform spent more than 200 seconds above the $100 \mathrm{~km}$ "Von-Karman" line in a free-space, hard vacuum environment. The experiment used a set of 2 by $2.5-\mathrm{N}$ thrusters, with each performing multiple restarts. This experiment used a set of photometers of the design described in this paper will be mounted at near the nozzle of one of the thrusters. A high-power, 3-color pulse-modulated LED will illuminate each sensor. Extensive ground test will be performed to measure the generated contaminants derived from simulated flight burn profiles. These results will be compared to the flight data derived for identical burn-time profiles, but under hard vacuum conditions. The data obtained from this flight indicated that even under hard vacuum conditions the sensors used for this project are capable of detecting the optical contamination. Additional hard vacuum tests will be conducted to determine how much contamination occurs over the life of the thrusters. 


\section{REFERENCES}

${ }^{i}$ Whitmore, et al., "Restartable Ignition Devices, Systems, and Methods Thereof," United States Patent Publication, Pub. No. US 2015/0322892 A1, Pub. Date: Nov. 12, 2015.

ii Anon., "Department of Defense Interface Standard, Eletromagnetic Environmental Effects requirements for Systems, MIL-STD464, http:// www.tscm.com/MIL-STD-464.pdf, [Retrieved 8 October 2012].

iii Whitmore, Stephen A., Peterson, Zachary W., and Eilers, Shannon D., "Comparing Hydroxyl Terminated Polybutadiene and Acrylonitrile Butadiene Styrene as Hybrid Rocket Fuels," J. Propulsion and Power, vol. 29, no. 3, May-June 2013.

iv Whitmore Stephen A, "Additively Manufactured Acrylonitrile-Butadiene-Styrene-Nitrous-Oxide Hybrid Rocket Motor with Electrostatic Igniter", J. Propulsion and Power, Vol. 31, No. 4 (2015), pp. 1217-1220.

${ }^{v}$ Whitmore, Stephen A., Inkley, Nathan R., Merkley, Daniel P. and Judson. Michael I, "Development of a Power-Efficient, Restart-Capable Arc Ignitor for Hybrid Rockets", J. Propulsion and Power, Vol. 31, No. 6 (2015), pp. 1739-1749.

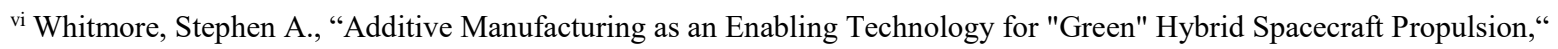
RAST-1039, Conference on Recent Advances in Space Technology 2015, Istanbul Turkey, June 16-19 2015, IEEE XPLORE, August 20 2015, DOI: 10.1109/RAST.2015.7208305

vii Whitmore, et al., "Solid Grain Structures, Systems, and Methods of Forming the Same," United States Patent Publication, Pub. No. US 2016/0194256 A1, Pub. Date: Jul. 7, 2016.

viii Nolte, William L., Kennedy, Brian C., and Dziegiel, Roger J. Jr., “USAF Technology Readiness Level Calculator,” NDIA Systems Engineering Conference, October 20, 2003, Available online at: www.dtic.mil/ndia/2003systems/nolte.ppt.

ix Cubbage, James M., "Investigation of Exhaust Backflow from a Simulated Cluster of Three Wide-Spaced Rocket Nozzles in a Near-Space Environment”, NASA Technical Note D-3016, September 1965.

x Jack, J.R., Spisz, E.W., and Cassidy, J.F, “The Effect of Rocket Plume Contamination on the Optical Properties of Transmitting and Reflecting Materials”, NASA Technical Memorandum X-67974, Tenth Aerospace Sciences Meeting sponsored by the American Institute of Aeronautics and Astronautics, San Diego, California, 17-19 January, 1972.

xi Fefferman, Charles L., "Existence and Smoothness of the Navier-Stokes Equation”, Clay Institute, https://www.claymath.org/sites/default/files/navierstokes.pdf

xii Bijiao, H., Jianhua, Z., and Guobiao, C., "Research on vacuum plume and its effects”, School of Astronautics, Beihang University, Beijing 100191, China, 14 October 2011.

xiii Soares, C., Barsamian, H., and Rauer, S., "Thruster Plume Induced Contamination Measurements from the PIC and SPIFEX Flight Experiments", SPIE Vol. 4774, 2002, Available online at http://spiedigitallibrary.org/ 
xiv He, B., Zhang, J., and Cai, G., "Research on Vacuum Plume and its Effects," Chinese J. of Aeronautics, Vol. 26, No. 1, Feb. 2013, pp 27-36.

${ }^{x v}$ Cha, J. and Co-authors, Engineering Plastics Handbook, chap. 6, "Acrylonitrile-Butadiene-Styrene (ABS) Resin", edited by J. M. Margolis, McGraw-Hill, 2006, pp. 101-130.

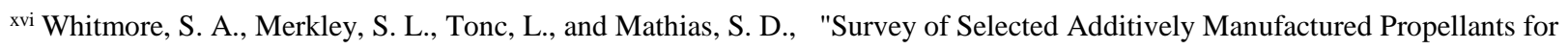
Arc Ignition of Hybrid Rockets", J. Propulsion and Power, Vol. 32, No. 6 (2016), pp. 1494-1504.

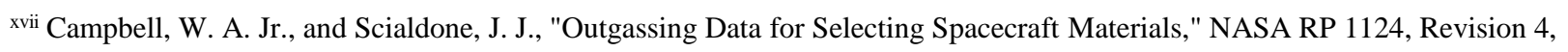
Jun 1997, http://outgassing.nasa.gov/cgi/uncgi/sectionc/sectionc.sh, [Retrieved 27 February 2014].

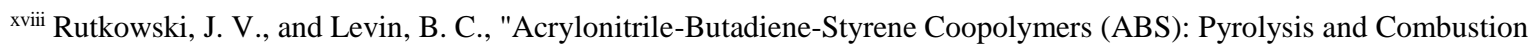
Products and their Toxicity - A Review of the Literature," J. Fire and Materials, Vol 10. No. 1, 1986, pp. 93-105.

xix Gordon, S., and McBride, B. J., "Computer Program for Calculation of Complex Chemical Equilibrium Compositions and Applications", NASA RP-1311, 1994.

${ }^{x x}$ Gordon, S., and McBride, B. J., "Computer Program for Calculation of Complex Chemical Equilibrium Compositions and Applications, Vol. 2, Users Manual and Program Descriptions”, NASA RP-1311, 1994.

${ }^{x x i}$ Whitmore, S. A., and Merkley, S. L., "Effects of Radiation Heating on Additively Printed Hybrid Fuel Grain O/F Shift", 52nd AIAA/SAE/ASEE Joint Propulsion Conference, AIAA Propulsion and Energy Forum, (AIAA 2016-4867) Salt Lake City UT USA, July 2016.

xxii I. D. Boyd and A. Ketsdever. "Interactions Between Spacecraft and Thruster Plumes", Journal of Spacecraft and Rockets, Vol. 38, No. 3 (2001), pp. 380-380. https://doi.org/10.2514/2.3712.

xxiii Bromaghim, D. R., Leduc, J. R., Salasovich, R. M., Spanjers, G. G., Fife, J. M., Dulligan, M. J., Schilling, J. H., White, D. C., and Johnson, L. K. "Electric Propulsion Space Experiment (ESEX) On-Orbit Results", Journal of Spacecraft and Rockets, Vol. 39, No. 2, March-April 2002, pp. 177-186.

xxiv Walker, James S., "Fast Fourier Transforms," CRC Press, Inc., Boca Raton FL, 1991, pp 34-76.

xxv Whimore, S.A., and Bulcher, A.M., "Vacuum Test of a Novel Green-Propellant Thruster for Small Spacecraft", AIAA-5044, 53rd AIAA/SAE/ASEE Joint Propulsion Conference, Propulsion and Energy Forum, Atlanta, GA, USA, July 10-12, 2017.

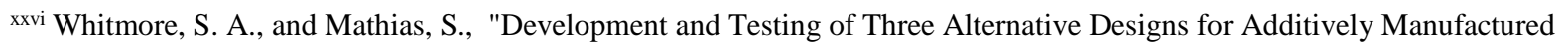
Hybrid Thrusters", AIAA 2016-4867, 52nd AIAA/SAE/ASEE Joint Propulsion Conference, Propulsion and Energy Forum, Salt Lake City, UT, USA, July 25-18, 2016. 
xxvii Haeseler, D., Bombelli, V., Vuillermoz, P., Lo, R., Marée, T., \& Caramelli, F., “Green Propellant Propulsion Concepts for Space Transportation and Technology Development Needs," ESA SP-557, Proceedings of the 2nd International Conference on Green Propellants for Space Propulsion, Cagliari, Sardinia, Italy, 7-8 June 2004.

xxviii Persson, M., Anflo, K., and Dinardi, A., “A Family of Thrusters For ADN-Based Monopropellant LMP-103S,” AIAA-20123815, 48th AIAA/ASME/SAE/ASEE Joint Propulsion Conference \& Exhibit, Atlanta, Georgia, 30 July - 01 August 2012.

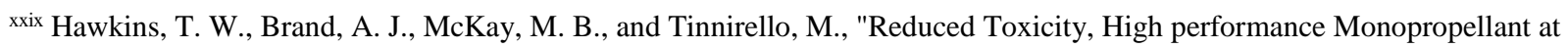
the U.S. Air Force research Laboratory," AFRL-RZ-ED-TP-2010-219, 4th International Association for the Advancement of Space Safety Conference, Huntsville, AL, 19-21 May 2010. 